\title{
Dietary interventions and cognition of Alzheimer's disease patients A systematic review of randomized controlled trial
}

\author{
Sophia Camargos Moreira ${ }^{\circledR}$, Ann Kristine Jansen ${ }^{1}{ }^{(0)}$, Flávia Moraes Silva ${ }^{\circledR}$
}

\begin{abstract}
It is estimated that by 2030 there will be 82 million people in the world with dementia. Objective: To evaluate the effect of dietary interventions on the cognitive performance of individuals with Alzheimer's disease (AD). Methods: A systematic review of randomized controlled trials (RCT) was conducted in the Scopus, PubMed, and Cochrane databases. Results: Thirty-two RCT were included. Omega-3 fatty acid showed positive effects at different doses. Fortasyn Connect seemed to be effective in the early stages of the disease. Probiotic, Ginseng, Inositol and specialized nutritional formulas seemed to have a positive effect on cognition. Most of the primary studies presented poor methodological quality, included patients with mild AD, small samples, and did not obtain significative results for all the cognitive outcomes. Conclusions: The effect of most dietary interventions on cognition in $\mathrm{AD}$ patients remains inconclusive, however, several nutrients, isolated or not, show potential to improve cognitive function in $A D$, especially in its early stages.
\end{abstract}

Keywords: Alzheimer's disease, diet, nutrients, dietary supplements, cognition.

\section{INTERVENÇÕES DIETÉTICAS E COGNIÇÃO EM PORTADORES DE DOENÇA DE ALZHEIMER: UMA REVISÃO SISTEMÁTICA DE ENSAIOS CLÍNICOS RANDOMIZADOS}

RESUMO. Estima-se que até 2030 haverá 82 milhões de pessoas no mundo com demência. Objetivo: Avaliar 0 efeito de intervenções dietéticas no desempenho cognitivo de indivíduos com DA. Métodos: Foi realizada uma revisão sistemática de ensaios clínicos randomizados (ECR) nas bases de dados Scopus, PubMed e Cochrane. Resultados: Trinta e dois ECRs foram incluídos. Ácidos graxos ômega-3 apresentaram efeitos positivos em diferentes doses. 0 Fortasyn Connect mostrou-se efetivo em estágios iniciais. Probióticos, Ginseng, Inositol e fórmulas nutricionais especializadas também demonstraram efeito positivo sobre a cognição. A maioria dos estudos primários apresentou baixa qualidade metodológica, incluiu pacientes com DA leve e amostras pequenas e não obteve resultados significativos para todos os desfechos cognitivos. Conclusões: 0 efeito da maioria das intervenções dietéticas em pacientes com DA permanece inconclusivo; entretanto, vários nutrientes, isolados ou não, apresentam potencial para melhorar a função cognitiva na DA, principalmente em seu estágio inicial.

Palavras-chave: doença de Alzheimer, dieta, nutrientes, suplementos nutricionais, cognição.

\section{INTRODUCTION}

It is estimated that by 2030 there will be 82 million people in the world with dementia. Most of these cases occur in middle- and low-income countries that currently hold $66 \%$ of all people with the disease. ${ }^{1}$ Alzheimer's disease $(\mathrm{AD})$ is the leading cause of dementia, representing 50 to $70 \%$ of dementia diagnoses in the population over 65 years of age. ${ }^{2,3}$ In Brazil, the epidemiological data on $\mathrm{AD}$ are still restricted to the most developed regions of the country, where the prevalence of dementia in the elderly ranges from 7.1 to $12.9 \%$, being $\mathrm{AD}$ the responsible for $55.1-59.8 \%$ of cases. ${ }^{4,5}$

Categorized as a progressive neurodegenerative disorder, $\mathrm{AD}$ has as its main physical and anatomopathological marker the abnormal accumulation of $\beta$-amyloid peptide $(\mathrm{A} \beta)$ in senile plaques (SP) and hyperphos-

This study was conducted at the Universidade Federal de Minas Gerais, Ringgold Standard Institution, Belo Horizonte, MG, Brazil.

'Universidade Federal de Minas Gerais, Ringgold Standard Institution - Belo Horizonte, MG, Brazil. 2Universidade Federal de Ciências da Saúde de Porto Alegre, Ringgold Standard Institution - Nutrition - Porto Alegre, RS, Brazil.

Sophia Camargos Moreira. Universidade Federal de Minas Gerais Ringgold Standard Institution. Av. Professor Alfredo Balena, 190 - Pampulha - $31270-901$ Belo Horizonte MG - Brazil. E-mail: sophiahcmoreira@gmail.com

Disclosure: The authors report no conflicts of interest.

Received on February 5, 2020. Accepted in its final form on May 4, 2020. 
phorylated tau protein (TP) in neurofibrillary tangles (NFT), resulting in diffuse cerebral atrophy in areas of the hippocampus and frontal, parietal and temporal cortex. ${ }^{2,6-8}$ The development of the disease includes a long preclinical period, with amyloid pathology being present 15 to 20 years before the onset of cognitive decline symptoms. ${ }^{2,6,9}$ Risk factors for $\mathrm{AD}$ include advanced age, presence of Apoliprotein E4 allele genes, family history of $\mathrm{AD}$ and brain injury. Increasing evidence also suggests that lifestyle-related modifiable risk factors such as inadequate diet, physical and intellectual inactivity, diabetes, obesity, depression, smoking, and low education have an important role in $\mathrm{AD}$ due to their relationship with mechanisms involving inflammation, oxidative stress, and mitochondrial dysfunction. ${ }^{3,6,7}$

To date, the therapeutic resources available for $\mathrm{AD}$ are limited to symptom management and cannot prevent cognitive decline and disease progression. Thus, there is a growing interest in strategies that can intervene in their pathophysiological mechanisms, targeting modifiable risk factors for the disease. ${ }^{6,8,10-12}$ In the field of $\mathrm{AD}$ prevention, scientific evidence on the role of diet is more robust. Prospective cohort studies with the Mediterranean Diet (MeDi), Dietary Approach to Stop Hypertension (DASH), and Mediterranean-DASH Diet Intervention for Neurodegenerative Delay (MIND) in healthy subjects demonstrated a lower incidence of $A D,{ }^{13}$ lower rates of cognitive decline, ${ }^{14-17}$ cerebral atrophy ${ }^{18}$ and $\mathrm{A} \beta$ deposition ${ }^{19}$ in the highest adherence scores to these diets. In two other studies, both $\mathrm{MeDi}$ and folate and vitamin $\mathrm{B} 6$ consumption were inversely associated with disease incidence. ${ }^{20,21}$

In the field of intervention, folate, $\mathrm{B} 6$ vitamin and other nutrients and dietary components have been studied for their neuroprotective properties and potential positive effect on cognition. Positive results in cognitive performance have been found in experimental studies and clinical trials using omega-3 fatty acids, ${ }^{8,11,12,22}$ alpha-lipoic acid, ${ }^{8,11,12}$ polyphenols, ${ }^{12,22,23}$ Q10 coenzyme, ${ }^{8,11,12}$ vitamin supplements, ${ }^{8,11,12,22,23}$ selenium, ${ }^{8}$ and phytochemicals. ${ }^{8,11,12,22,23}$ However, several questions are still present regarding the reproducibility of the results found in animal models and the effectiveness of such interventions in individuals with $\mathrm{AD}$ in the various stages of the disease.

Therefore, considering the potential relationship between diet, cognition and $\mathrm{AD}$, the present systematic review aimed to evaluate the existing evidence in controlled randomized controlled trials for the use of specific dietary interventions in the management of cognitive decline in $\mathrm{AD}$ patients.

\section{METHODS}

It was a systematic review of randomized controlled trials conducted according to the protocol proposed by the Cochrane Collaboration ${ }^{24}$ and structured as proposed by the Preferred Reporting Items for Systematic Reviews and Meta-Analyzes (PRISMA). ${ }^{25}$

\section{Literature search strategy}

The search for randomized controlled trials (RCT) was conducted in the PubMed, Cochrane Central Register of Controlled Trials, and Scopus databases, in September 2016, using a combination of the Medical Subject Heading (MeSH) terms related to the factor under study (dietary interventions in Patients with AD), outcome (cognitive performance), and design (randomized controlled trials) (Table 1). Additionally, manual searches were performed in the reference list of studies relevant to this review.

\section{Selection of eligible studies}

The studies identified in the search in the three databases were stored in the reference organizer program Endnote Web, after deleting duplicates. Two reviewers (AKJ and SHCM) independently assessed the titles and abstracts and the discrepancies were resolved by a third reviewer (FMS). After the selection of potentially eligible articles, a reviewer (SHCM) read the full texts for confirmation of inclusion in this systematic review and collected the data from a standardized form.

Table 1. Pubmed search strategy. 
The following criteria were considered eligible for the two stages of study selection:

- A randomized clinical trial design.

- Including participants with a prior diagnosis of AD.

- Having assessed cognition as primary or secondary endpoint.

- Having had interventions such as diet or food or specific supplement.

Studies that included participants with different types of dementia and did not present stratified results for $\mathrm{AD}$ were excluded, as were those whose presented open-label phase results from an included study and whose full text could not be accessed. Only studies whose manuscript were published in English were selected.

\section{Data extraction and methodological quality assessment of eligible studies}

The data extracted from the articles were:

- Authorship.

- Date of publication.

- Country where the study was conducted.

- Study design.

- Method of randomization.

- Blinding of participants, researchers, and evaluators.

- Sample size and proportion of subjects completing the study.

- Inclusion and exclusion criteria.

- Criteria used to diagnose ad.

- Mean age of participants.

- Proportion of male subjects.

- Dietary intervention protocol.

- Cognitive outcomes analyzed.

- Main results.

To evaluate the methodological quality, the criteria proposed by Cochrane were evaluated from the six domains: randomization method, allocation concealment, blinding scheme (participants, professionals, and outcome assessors), intention-to-treat analysis (ITT), follow-up losses and selection of outcomes. ${ }^{24}$

\section{RESULTS}

From the search in the three databases, 5,000 articles were identified, after duplicate exclusion. Additionally, nine articles considered relevant to the study were included. Thirty-two studies met the eligibility criteria and were included in this review. The study flowchart is presented in Figure 1.

\section{General characteristics of studies}

The overall characteristics of the selected studies are presented in Table 2 . The majority were conducted in the United States (41.0\%) and in European countries (34.0\%). The sample size ranged from 12 to 613 individuals per test with a follow-up period of 25 weeks in men, ranging from three weeks to thirty months. The mean age of participants ranged from 66.1 to 84.8 years and in seven studies (22\%), more than half of the sample consisted of men.

Of the 32 RCT included, one (3\%) had a cross-over design, ${ }^{57} 26(87 \%)^{27,29,31-47,50,51,53-57}$ were placebo-controlled, five $(16 \%)^{26,28,30,48,49}$ used a conventional control treatment, and one $(3 \%)^{52}$ compared dietary intervention with pharmacological treatment. Regarding the blinding scheme, $26(81 \%)$ trials were double-blind, ${ }^{27,29,31-42,44-47,50-57}$ four (13\%) were open ${ }^{28,30,48,49}$ and two (6\%) were single blind. ${ }^{26,43}$

In most trials (59\%), the diagnosis of $\mathrm{AD}$ was based on the criteria of the National Institute of Neurological and Communicative Disorders and Stroke and the Alzheimer's Disease and Related Disorders Association (NINCDS-ADRDA) and the Diagnostic and Statistical Manual of Mental Disorders (DSM-III and DSM-IV). In one study, ${ }^{33}$ the International Working Group/National Institute of Aging-Alzheimer's Association (IWG/NIAAA) criteria were used for the diagnosis of prodromal Alzheimer's.

The intervention period in the studies ranged from three weeks to three and a half years. For the assessment of cognitive performance, different instruments were used, being the Mini-Mental State Examination (MMSE), Alzheimer's Disease Assessment Scale-Cognitive Subscale (ADAS-cog), and Clinical Dementia Rating Scale - Sum of Boxes (CDR-SOB) the most frequent tests adopted.

\section{Effect of dietary interventions on the cognition of patients with Alzheimer's disease}

The effect of different dietary interventions on the cognition of $\mathrm{AD}$ patients evaluated by the studies is presented in Table 2, grouped by the type of intervention. Dietary interventions were grouped as oral nutritional formulations, fatty acids (alone or in combination with other nutrients), micronutrients (alone or in combination with other nutrients), ginseng, phytochemicals, coconut oil, probiotics, and inositol. Details of the effects of each intervention are detailed below. 


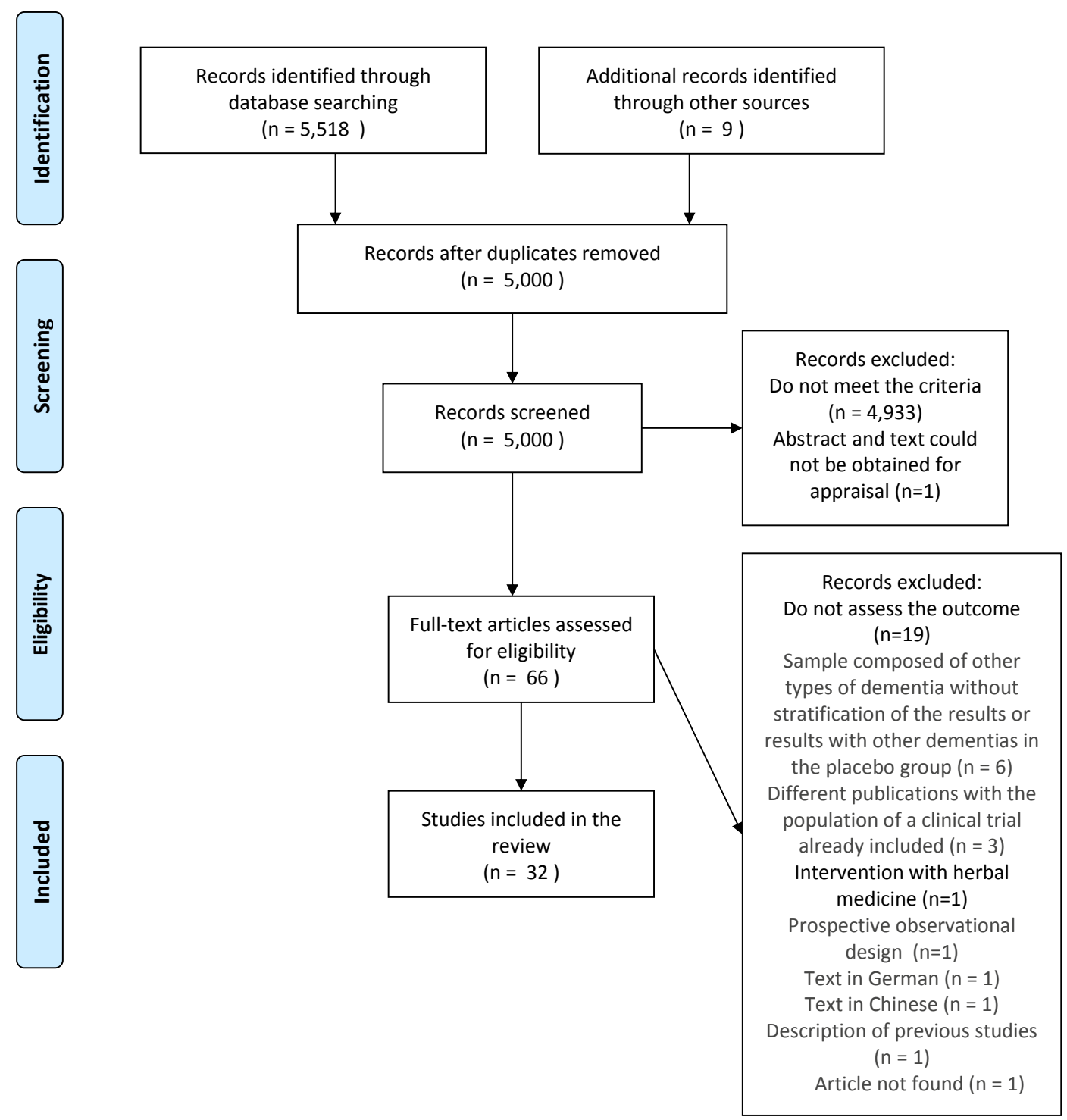

From: Moher D, Liberati A, Tetzlaff J, Altman DG, The PRISMA Group (2009). Preferred Reporting /tems for Systematic Reviews and MetaAnalyses: The PRISMA Statement. PLoS Med 6(7): e1000097. doi:10.1371/journal.pmed1000097

For more information, visit www.prisma-statement.org.

Figure 1. Prisma flow diagram.

\section{Oral nutritional formulations}

Eight parallel RCT ${ }^{26-33}$ evaluated the effect of intervention with ONF on the cognitive performance of patients with AD. Sample sizes ranged from 37 to 528 subjects, most of whom had mild cognitive decline (MMSE > 15 at baseline). Supplements tested included either liquid or semi-solid formulations, offered one to three times a day.

There was heterogeneity among the studies regarding the macro and micronutrient composition of the supplements, trial design, intervention duration (21 days to 24 months), and cognitive outcomes evaluated.
Three RCT tested the same supplement. In these, the use of omega-3, phospholipids, choline, uridine monophosphate, vitamin $\mathrm{E}$, vitamin $\mathrm{C}$, selenium, vitamin B12, vitamin B6, and folic acid enriched formula resulted in a lower decline in the Wechsler Memory Scale - revised immediate recall ${ }^{29}$ and better memory domain performance in the Neuropsychological Test Battery $(\mathrm{NTB})^{31}$ in patients with mild AD and less worsening in the CDR-SOB in patients with prodromal AD. ${ }^{33}$ Among the other studies, one evaluated the same previous formulation in patients with mild to moderate $\mathrm{AD},{ }^{32}$ 

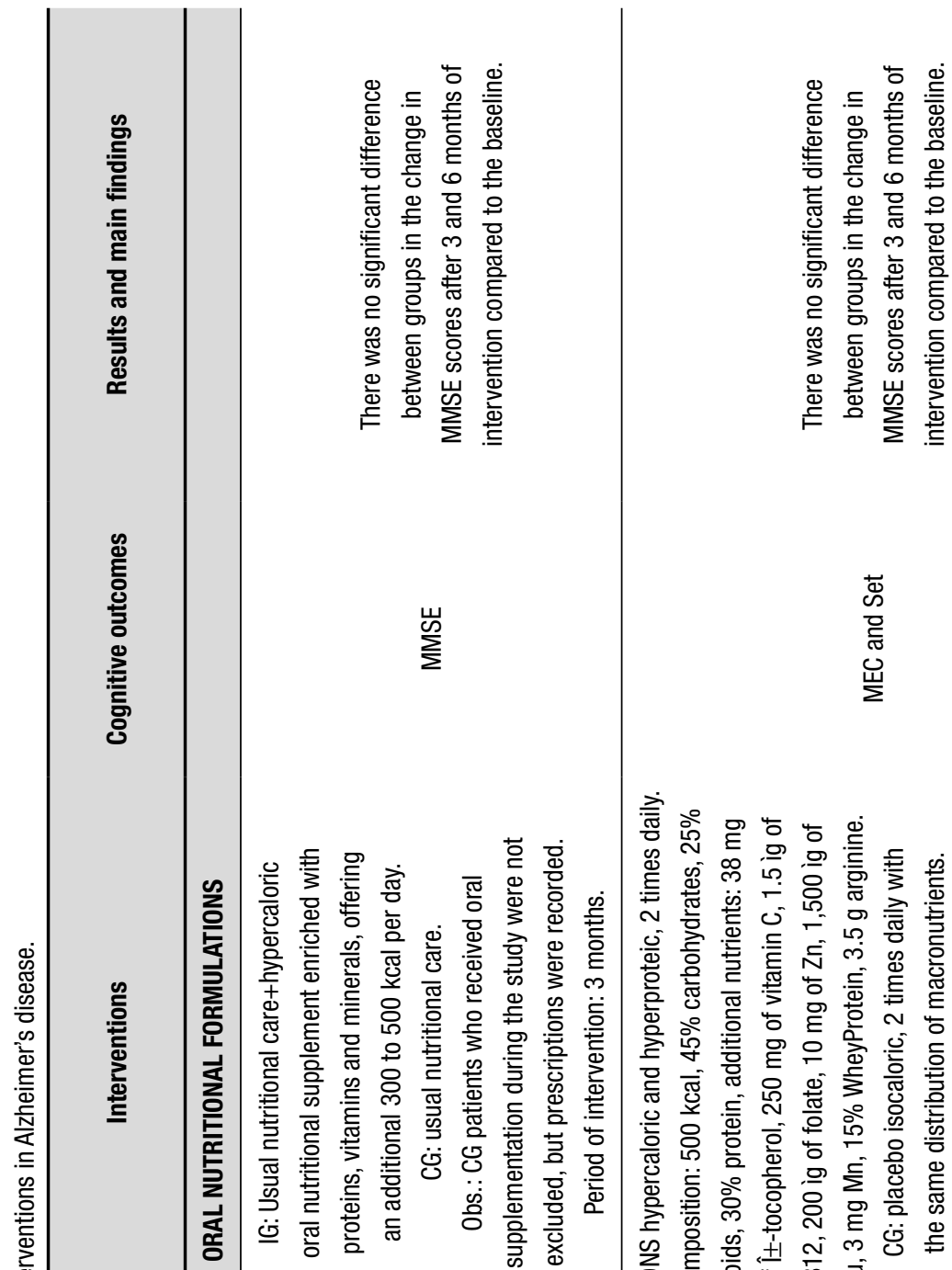

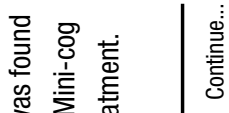

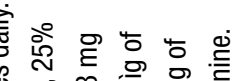

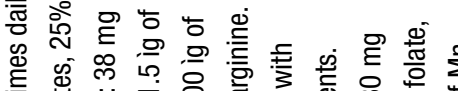

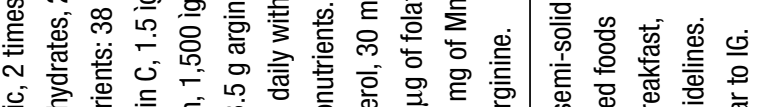

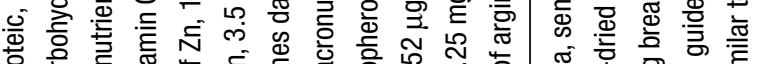

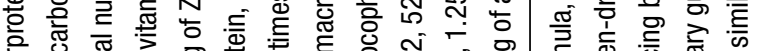

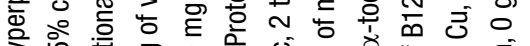

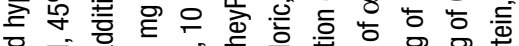

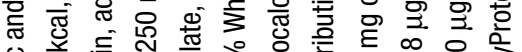

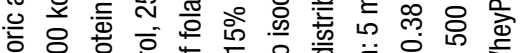
ㄸ⿺ㄴ

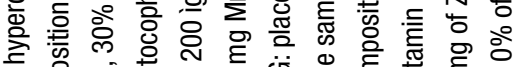

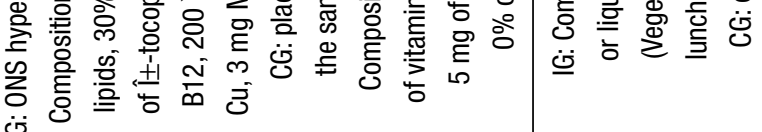

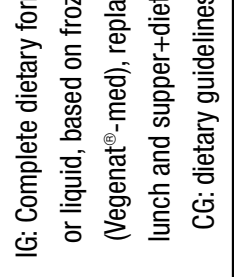
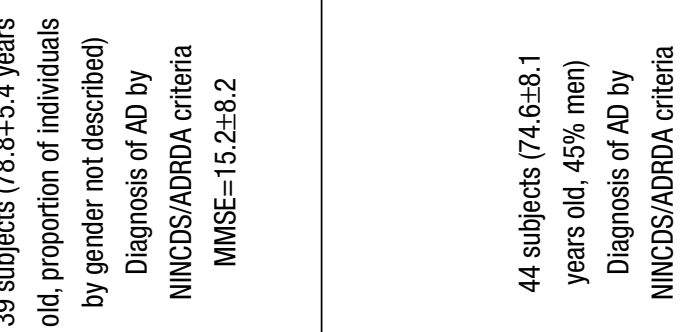

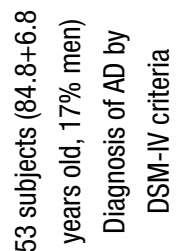
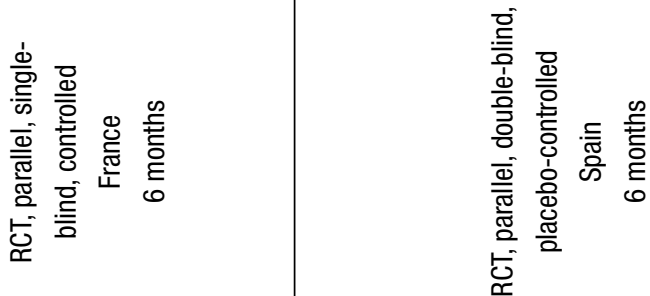

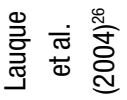

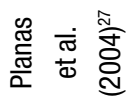

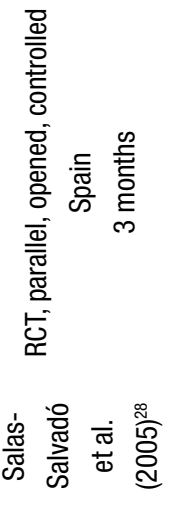




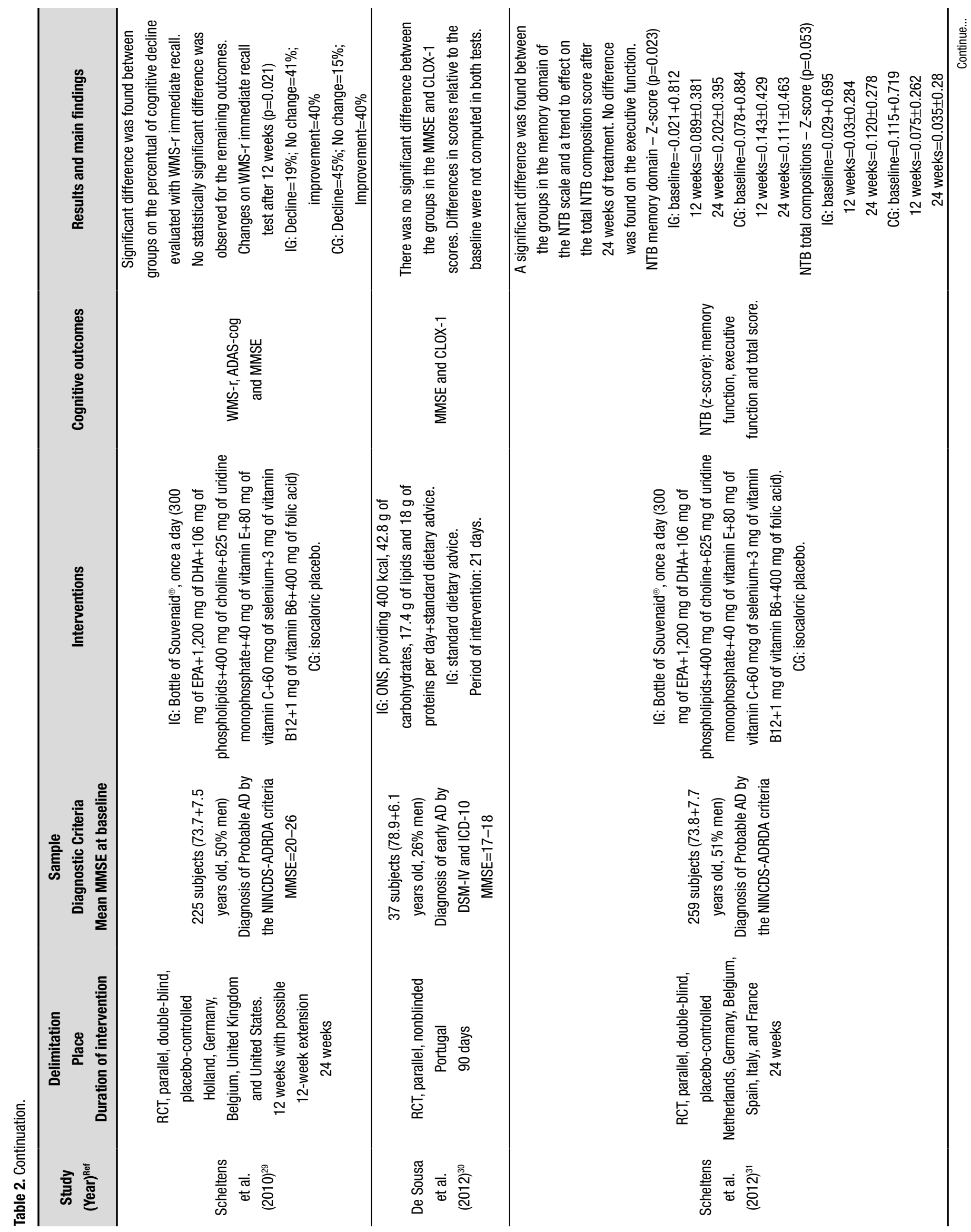




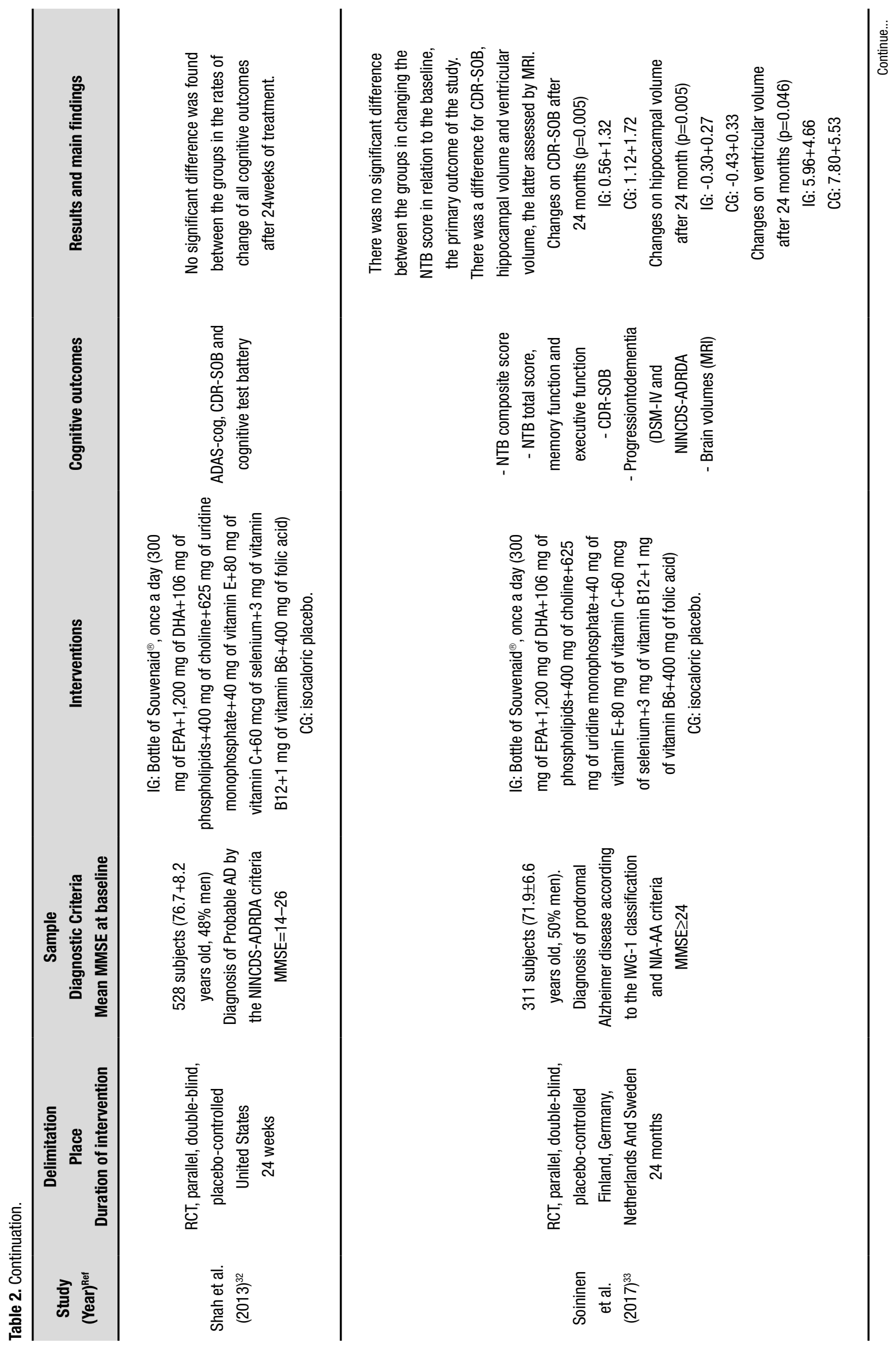




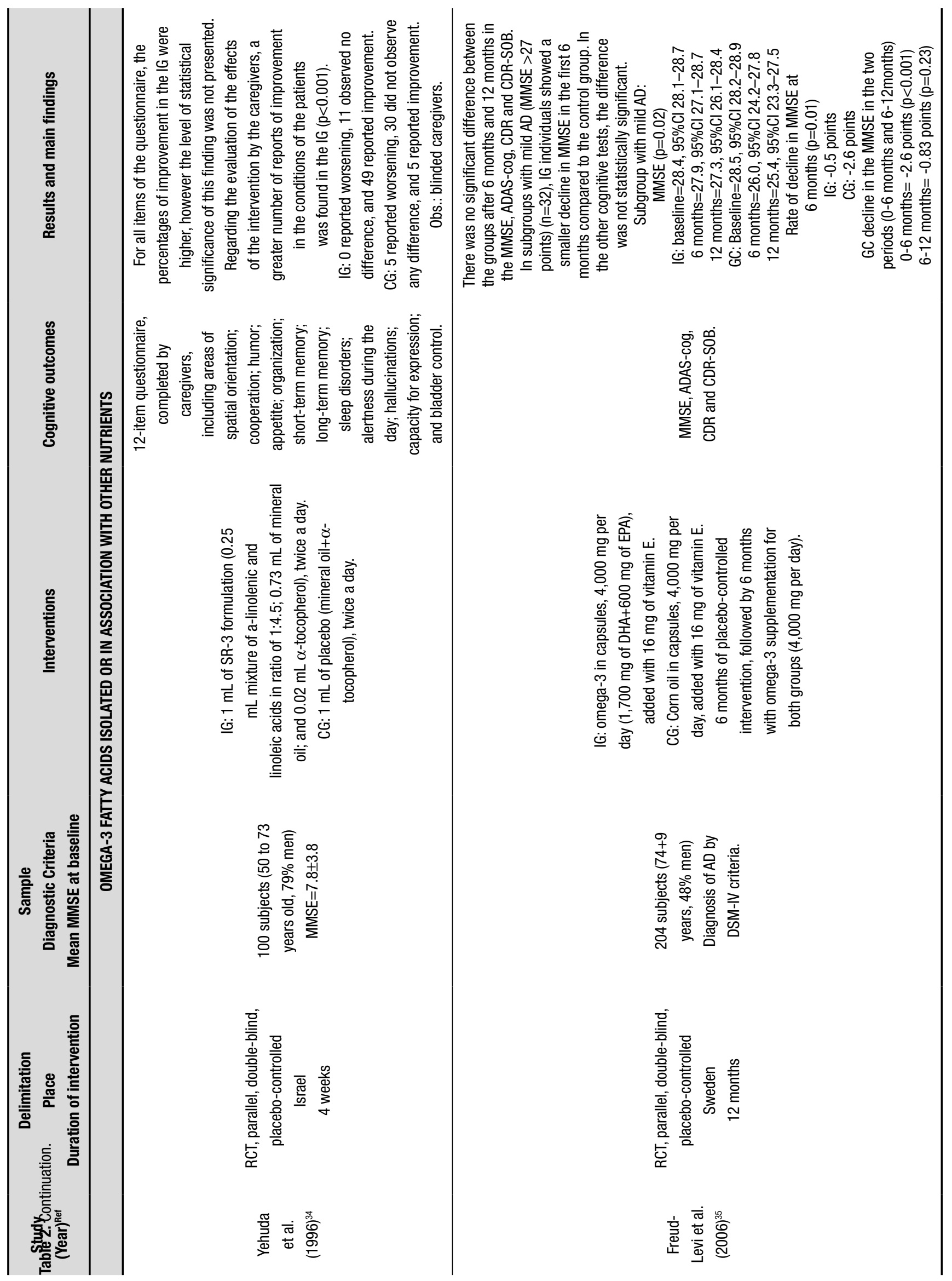




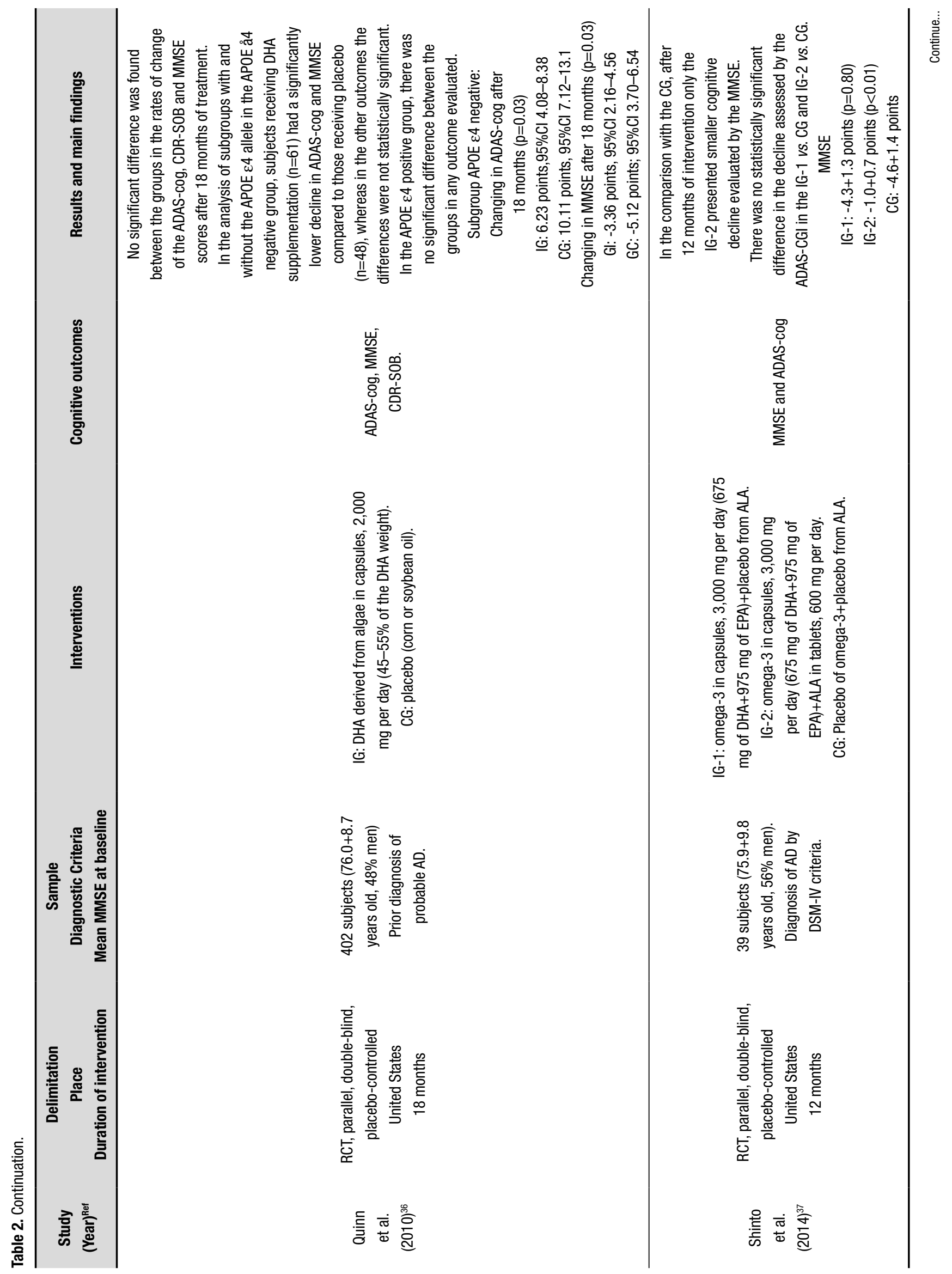




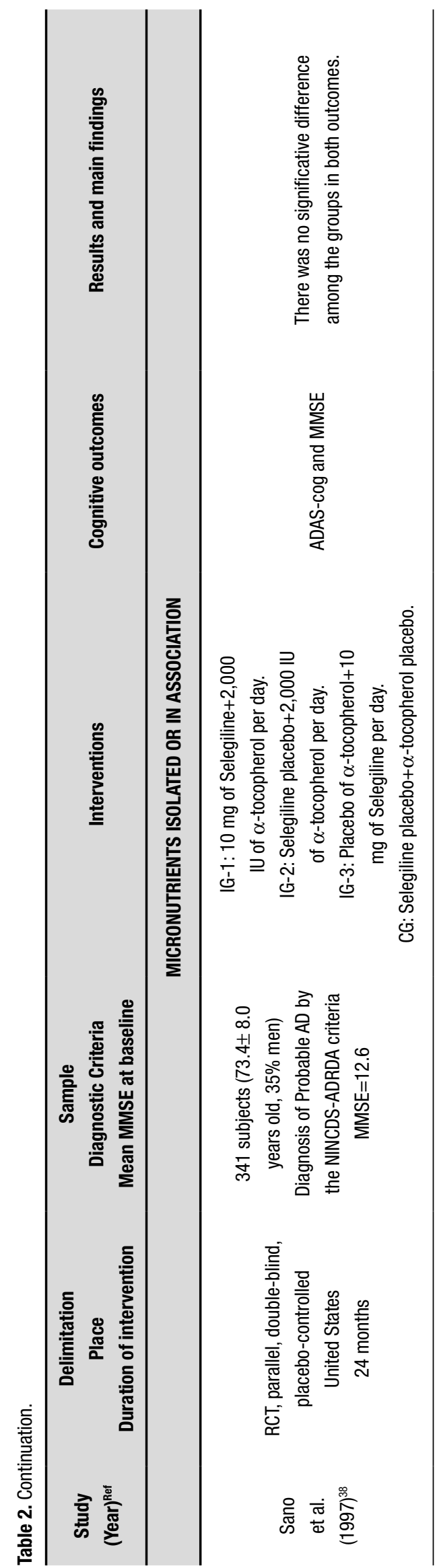

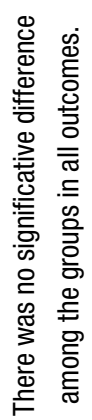

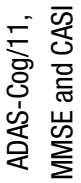

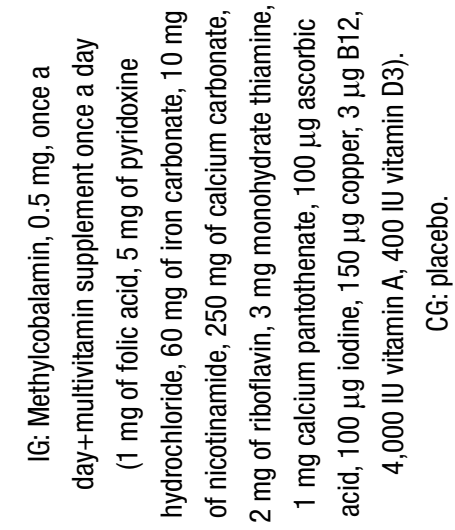

พ

+o

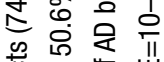

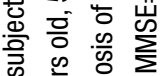

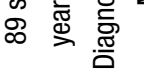

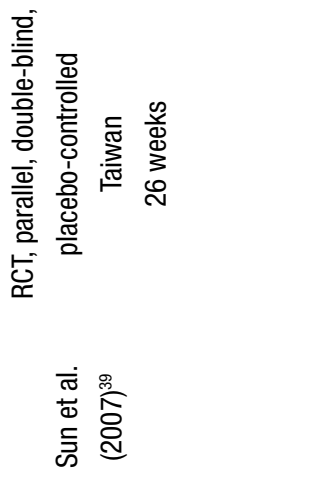

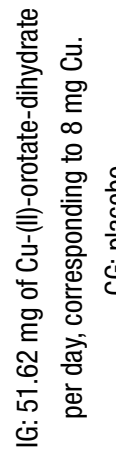

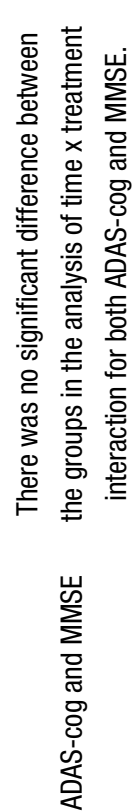

通

迹密

흫

늘 흥

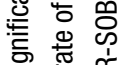

का

要.

$\sum_{0}$

흩 흥

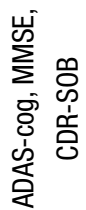

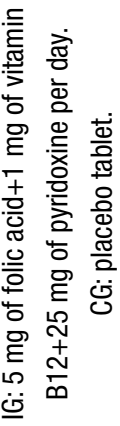

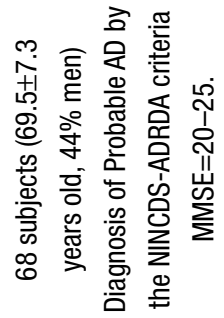

울

m

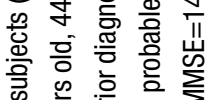
क क

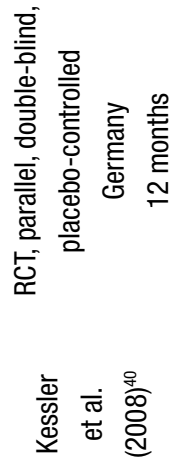




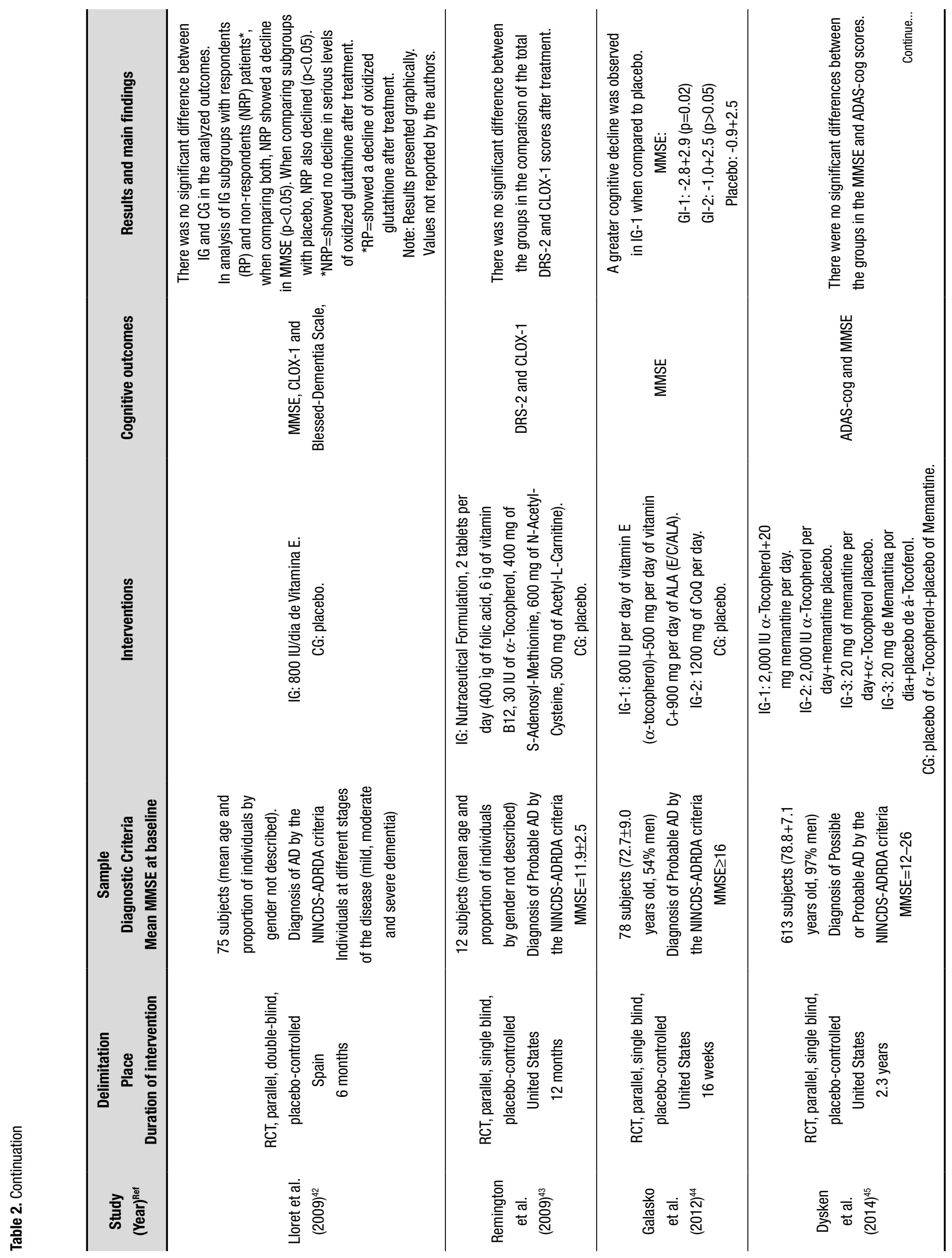




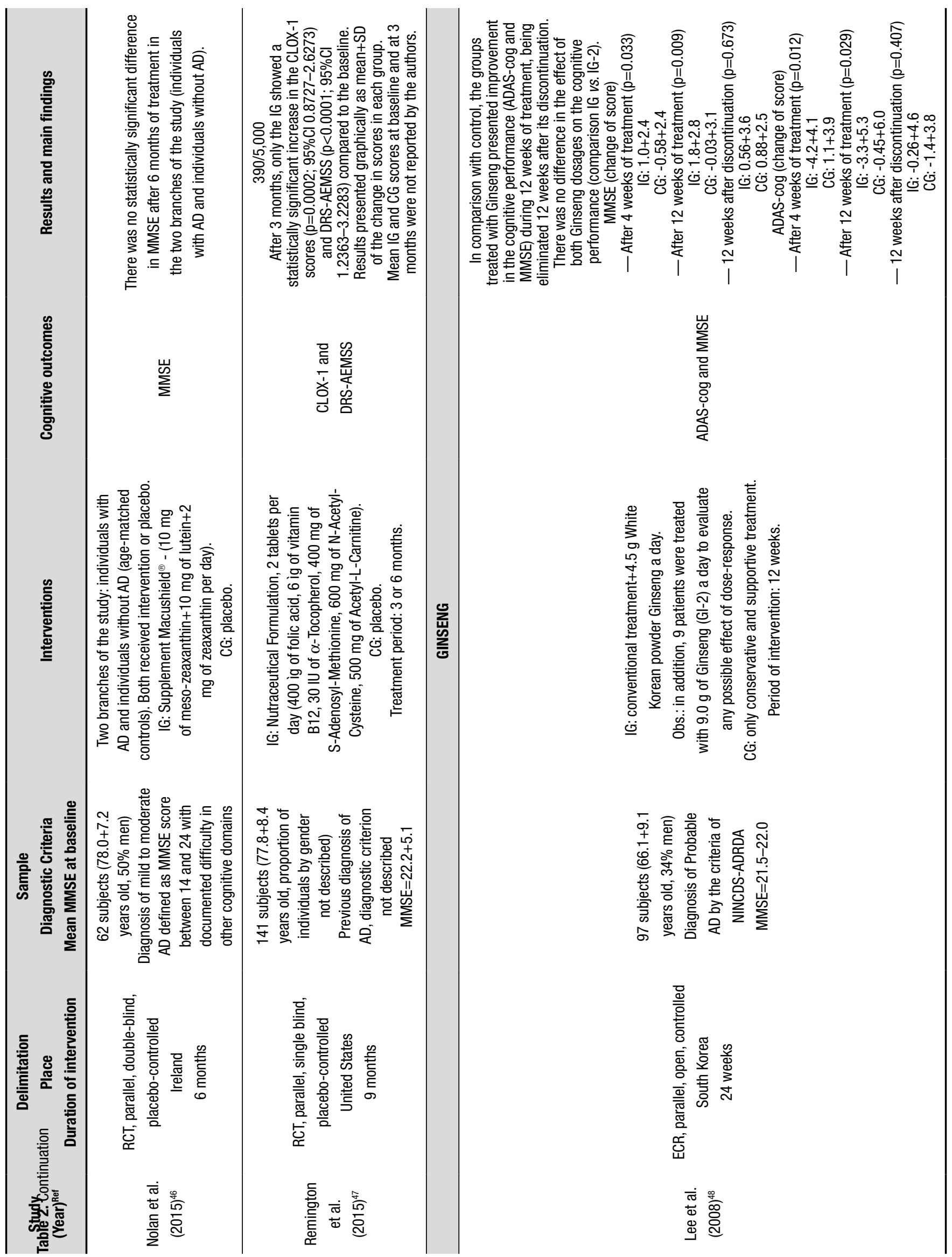




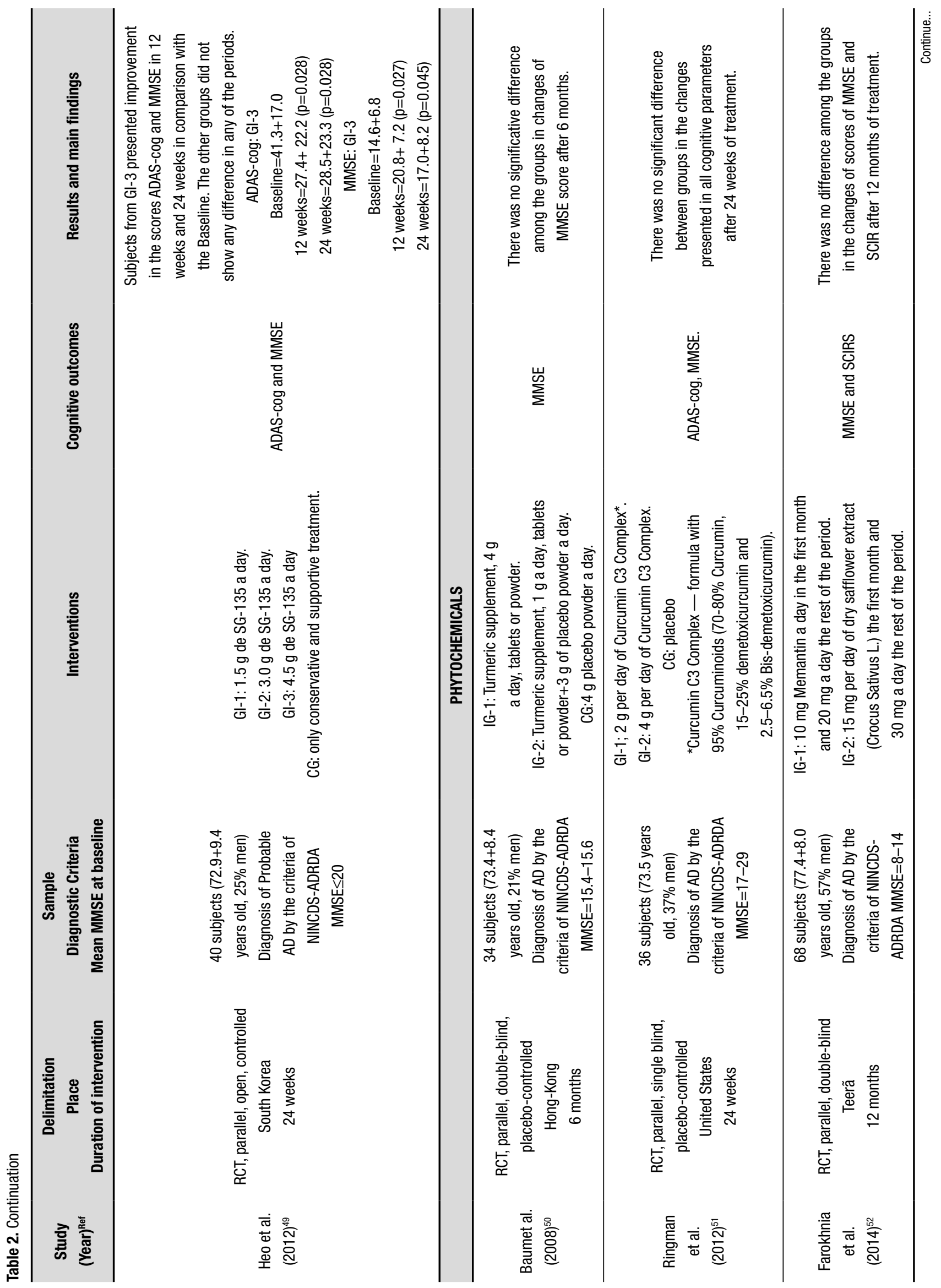




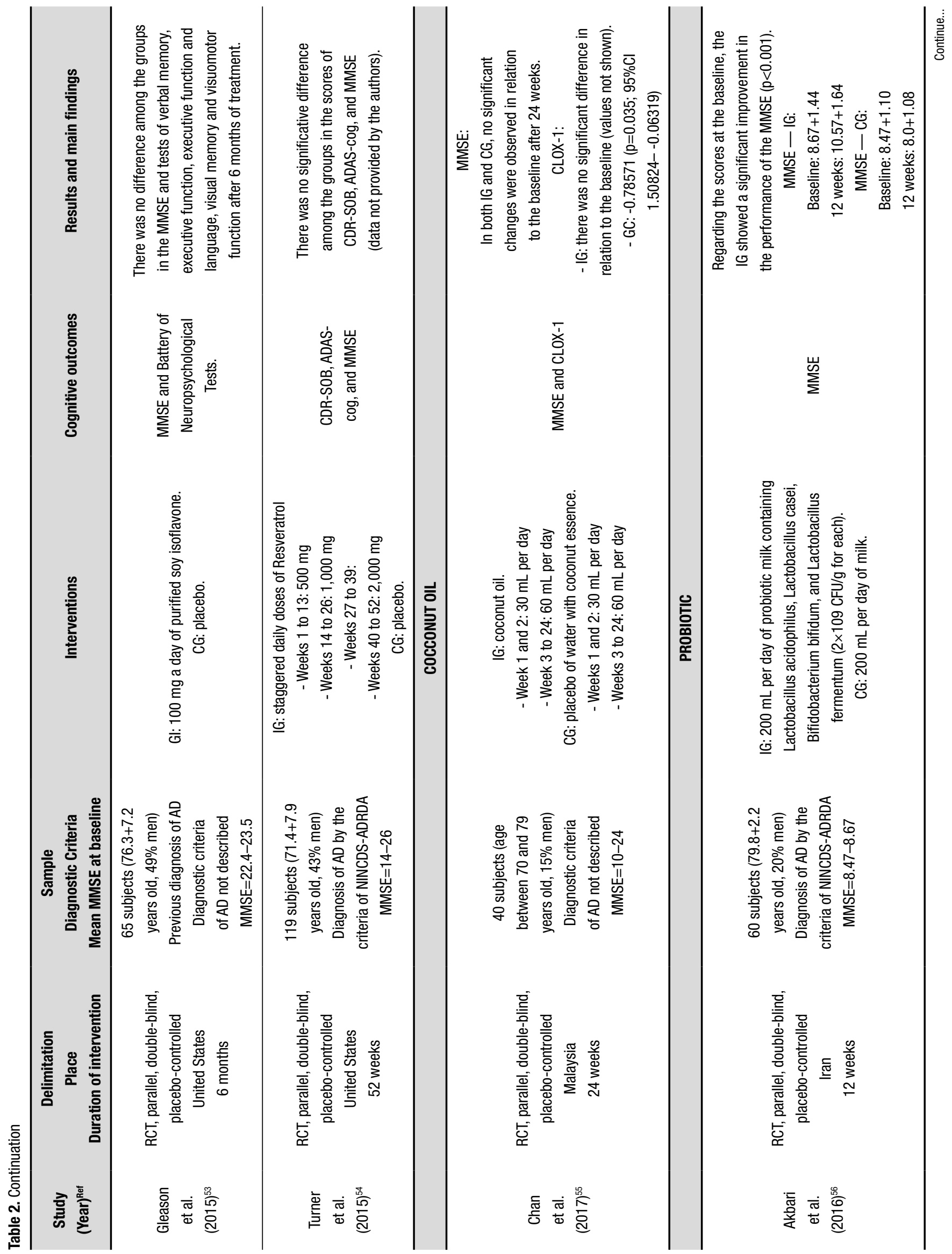




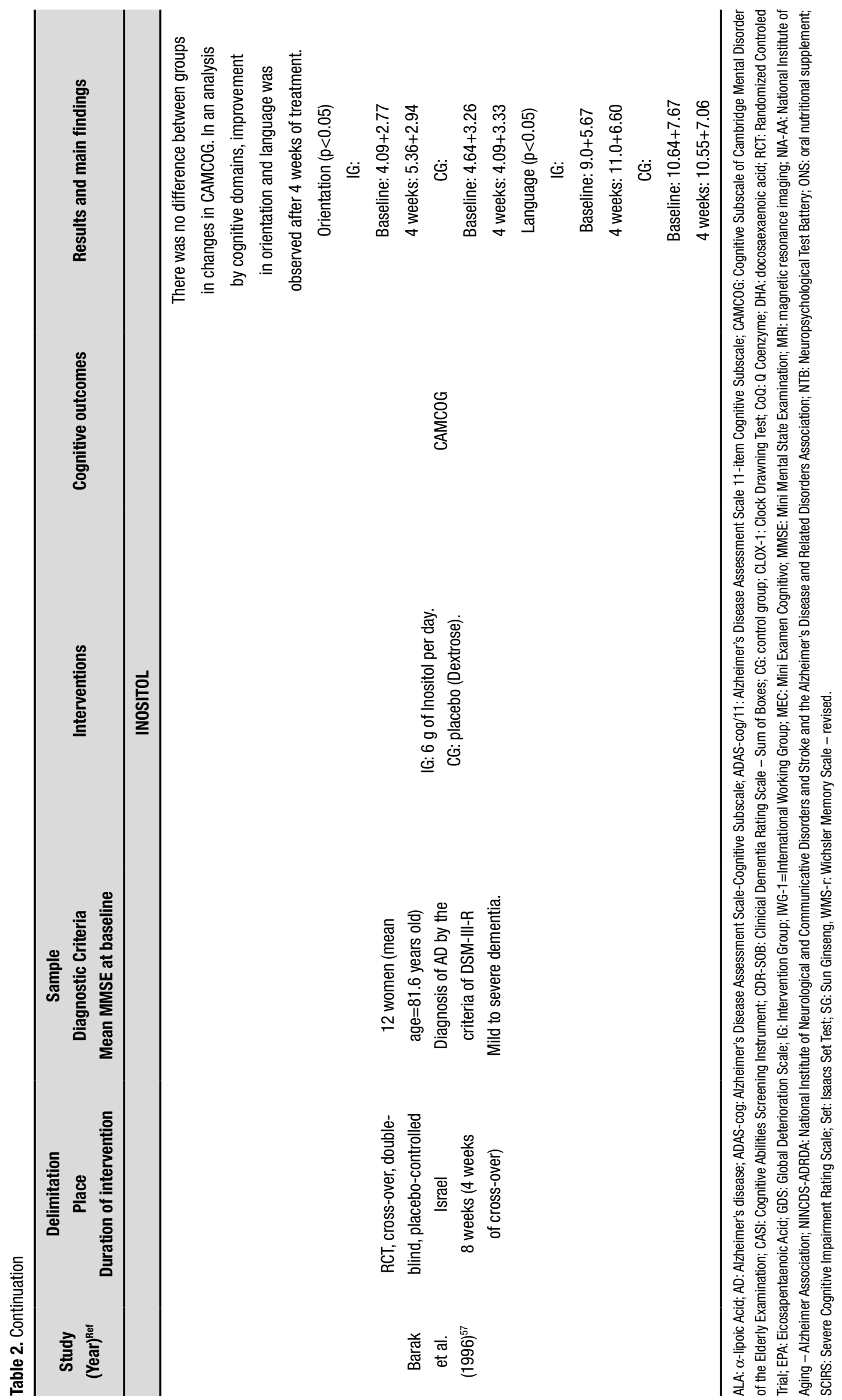


three $e^{26,27,30}$ evaluated hypercaloric and hyperprotein supplements with different micronutrient compositions and one analyzed a complete dietary formula based on lyophilized foods. ${ }^{28}$ None of them, however, found statistically significant effects on the cognitive outcomes evaluated.

The randomization method used to allocate participants was described in six studies (Table 3), two of which used computer-generated block randomization, ${ }^{29,33}$ two had central randomization from codes, ${ }^{31,32}$ one used sequential numbers that were kept in sealed envelope ${ }^{26}$ and a centralized randomization stratified by the initial body mass index. ${ }^{28}$ Of the eight RCT, two were opened ${ }^{28,30}$ and five reported blinding of researchers and outcome evaluators. ${ }^{27,29,31-33}$ The groups studied were comparable at baseline in seven trials. ${ }^{26-32}$ Regarding the evaluated outcomes, only one study did not present the results of all pre-established outcomes. ${ }^{26}$ Seven of the trials reported follow-up losses, ${ }^{26,28-32}$ which was greater than $10 \%$ in five studies. ${ }^{26,28,29,32,33}$ Among those with losses, ${ }^{26,29-32}$ six performed ITT and one ${ }^{28} \mathrm{did}$ not report the type of analysis performed.

\section{Fatty acids}

Four parallel $\mathrm{RCT}^{34-37}$ tested the effect of fatty acid supplementation alone or associated with other nutrients on cognitive outcomes in individuals with $\mathrm{AD}$. The duration of interventions varied between 4 weeks and 18 months and the trials were heterogeneous in relation to the sample size (39-582 participants per trial), dose used, presence of vitamin $\mathrm{E}$ and $\alpha$-lipoic acid (ALA), composition and fatty acid content (isolated docosahexaenoic acid (DHA), DHA+eicosapentaenoic acid (EPA) and mixture of $\alpha$-linolenic acid with linoleic acid).

In all four studies, fatty acid supplementation resulted in significant improvement in part of the cognitive parameters analyzed. Twelve-month supplementation with 5,800 mg per day of omega-3 associated with vitamin $\mathrm{E}$ in patients with mild $\mathrm{AD}$ was effective in promoting a lower rate of cognitive decline on MMSE, but only in the first six months of treatment..$^{35}$ Smaller decline on MMSE was also observed with the use of omega-3 associated with ALA in mild AD (3,000 mg of omega-3+600 mg of ALA per day) ${ }^{37}$ and the use of seaweed-derived DHA (2,000 mg per day, $45-55 \%$ of DHA) has shown to be beneficial for patients with negative Apoliprotein E (APOE) $\varepsilon 4$ allele, being able to reduce the cognitive decline assessed by ADAS-cog. ${ }^{36}$

In patients with advanced AD (baseline MMSE=7.8+3.8), the use of $2 \mathrm{~mL}$ per day of a formulation containing a mixture of $\alpha$-linolenic and linoleic in a ratio of 1:4.5 combined with $\alpha$-tocopherol resulted in more reports by caregivers of improvement in the patients' general condition. ${ }^{34}$

Regarding methodological quality, one of the trials used a block randomization method based on an interactive voice response system with stratification by center, ${ }^{36}$ one had computer-generated randomization with stratification by smoking, ${ }^{37}$ and the others did not describe the randomization method used to allocate participants..$^{34,35}$ The groups studied were comparable at baseline in only one ${ }^{35}$ of the four RCT, and one of the remaining RCT this data was not reported. ${ }^{34}$ Three tri$\mathrm{als}^{35-37}$ showed follow-up losses, all greater than $10 \%$. Of these, 36 performed the ITT and one did not report the type of analysis performed ${ }^{34}$ Regarding the evaluated outcomes, only one study ${ }^{37}$ did not present the results of all pre-established outcomes.

\section{Micronutrients}

Ten parallel RCT evaluated micronutrient supplementation alone or in combination compared to placebo $^{39-44,46,47}$ or pharmacological treatment. ${ }^{38,45}$ There was heterogeneity in relation to blinding (nine double-blind and one-blind), sample size (12-613 participants per trial), duration of intervention (16 weeks to 4 years), assessed cognitive outcomes and nutrients used $\left(\alpha\right.$-tocopherol alone,,$^{38,42,45} \mathrm{~B}^{41}$ vitamins association, carotenoid association, ${ }^{46}$ copper, ${ }^{58}$ coenzyme $Q,{ }^{44}$ multivitamin and mineral supplement, ${ }^{39}$ vitamins associated with $\mathrm{ALA}^{44}$ and nutraceutical formulation containing vitamins, minerals, and peptides). ${ }^{43,47}$

In patients with mild $A D(M M S E=22.2+5.1)$, the use of a nutraceutical formula containing folic acid, vitamin B12, $\alpha$-tocopherol, S-adenosyl methionine, $\mathrm{N}$-acetyl cysteine, and acetyl-L-carnitine resulted in significant improvement in the Clock Drawing Test (CLOX-1) and the Age- and Education-adjusted Dementia Rating Scale (DRS-AEMSS) scores compared to baseline. ${ }^{47}$ Such result differs from the pilot RCT performed with the same formulation, where no significant differences were found between groups in DRS-2 and CLOX-1. ${ }^{43}$

Copper orotate supplementation was also evaluated in a group of patients with mild AD (MMSE=20-25). Both the intervention and control groups showed an increase in the ADAS-cog score and a reduction in MMSE performance in relation to the baseline. These results were statistically significant. In the comparison between groups, the increase in ADAS-cog was smaller in the supplemented group, indicating lower cognitive decline. There was no difference between the groups regarding MMSE performance. ${ }^{58}$ 


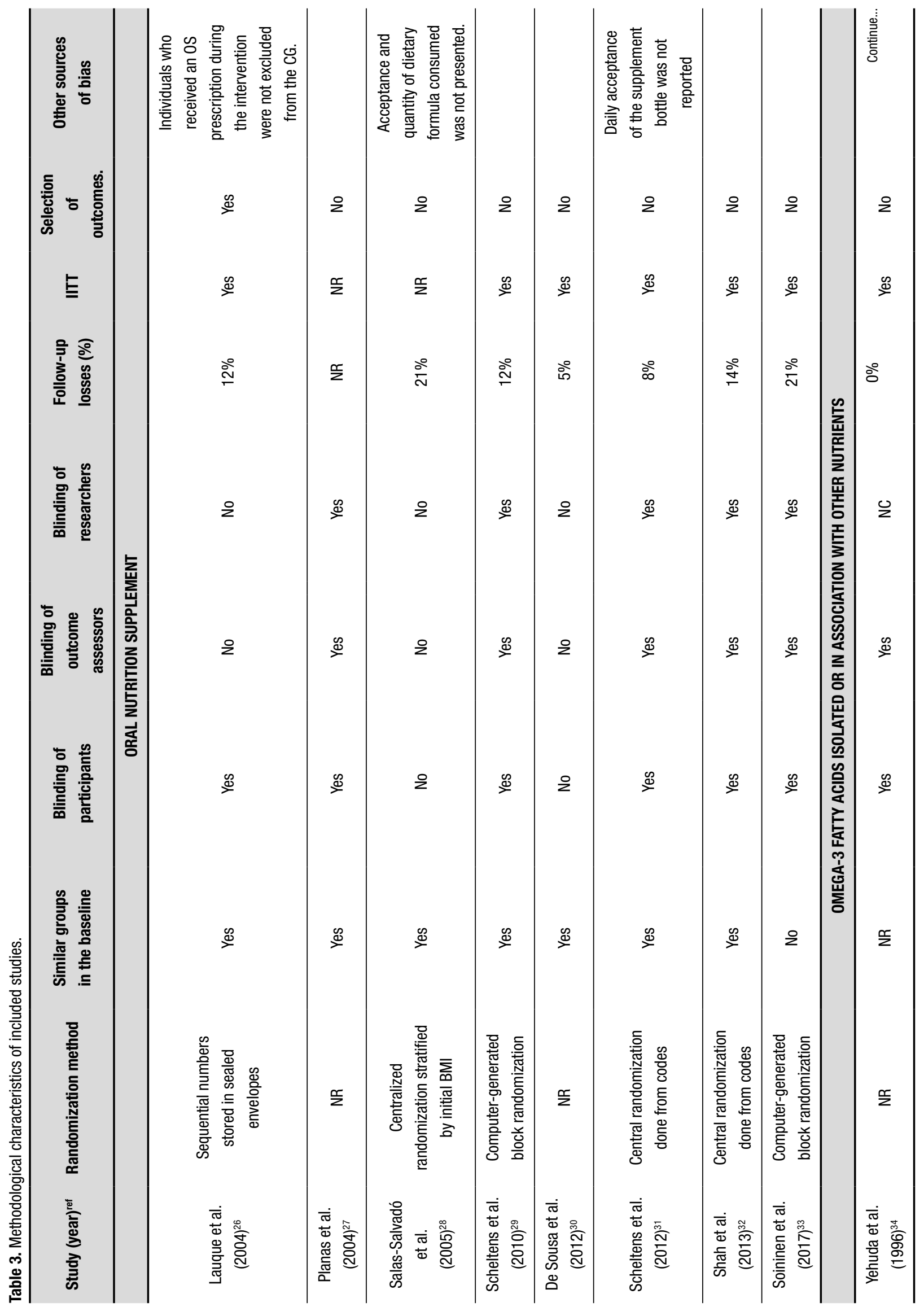




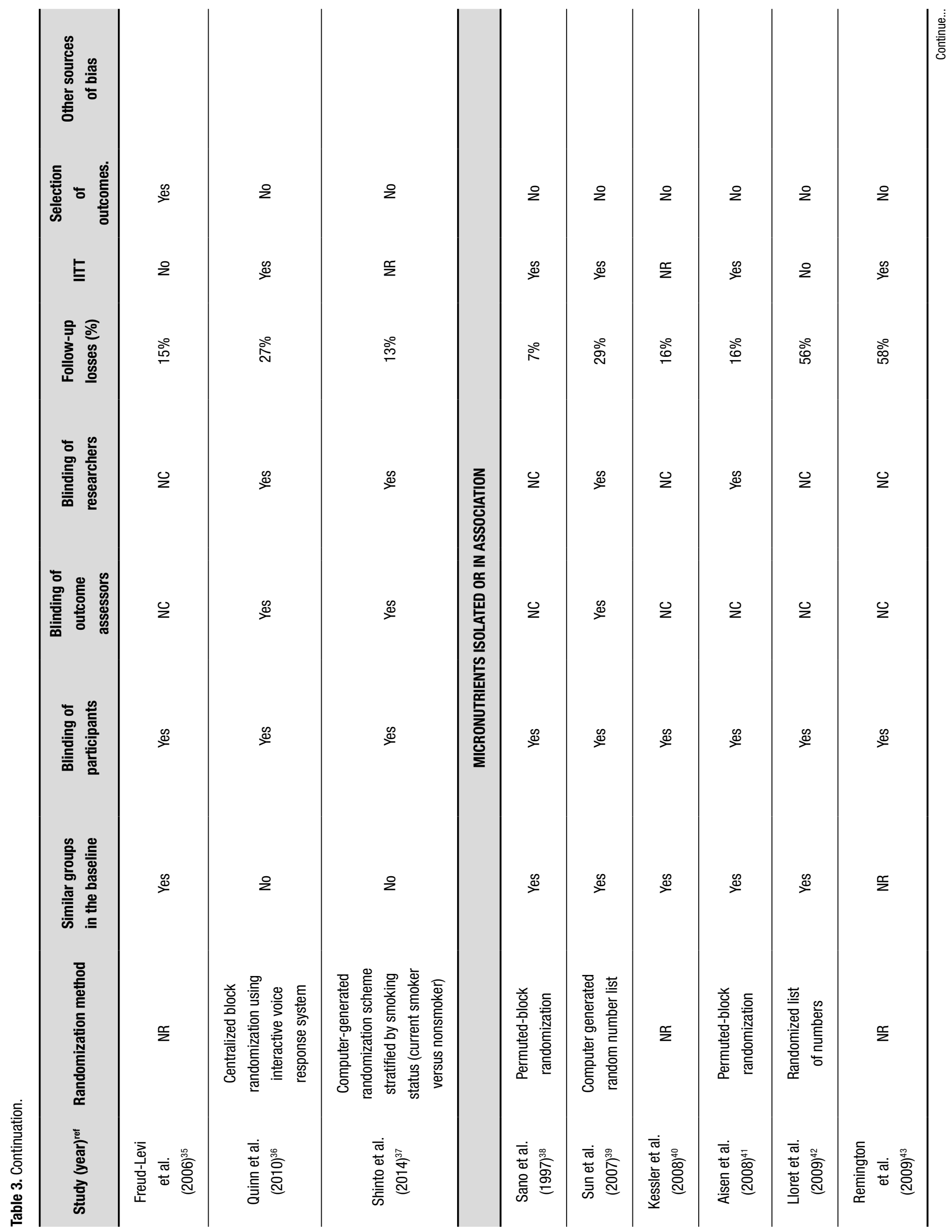




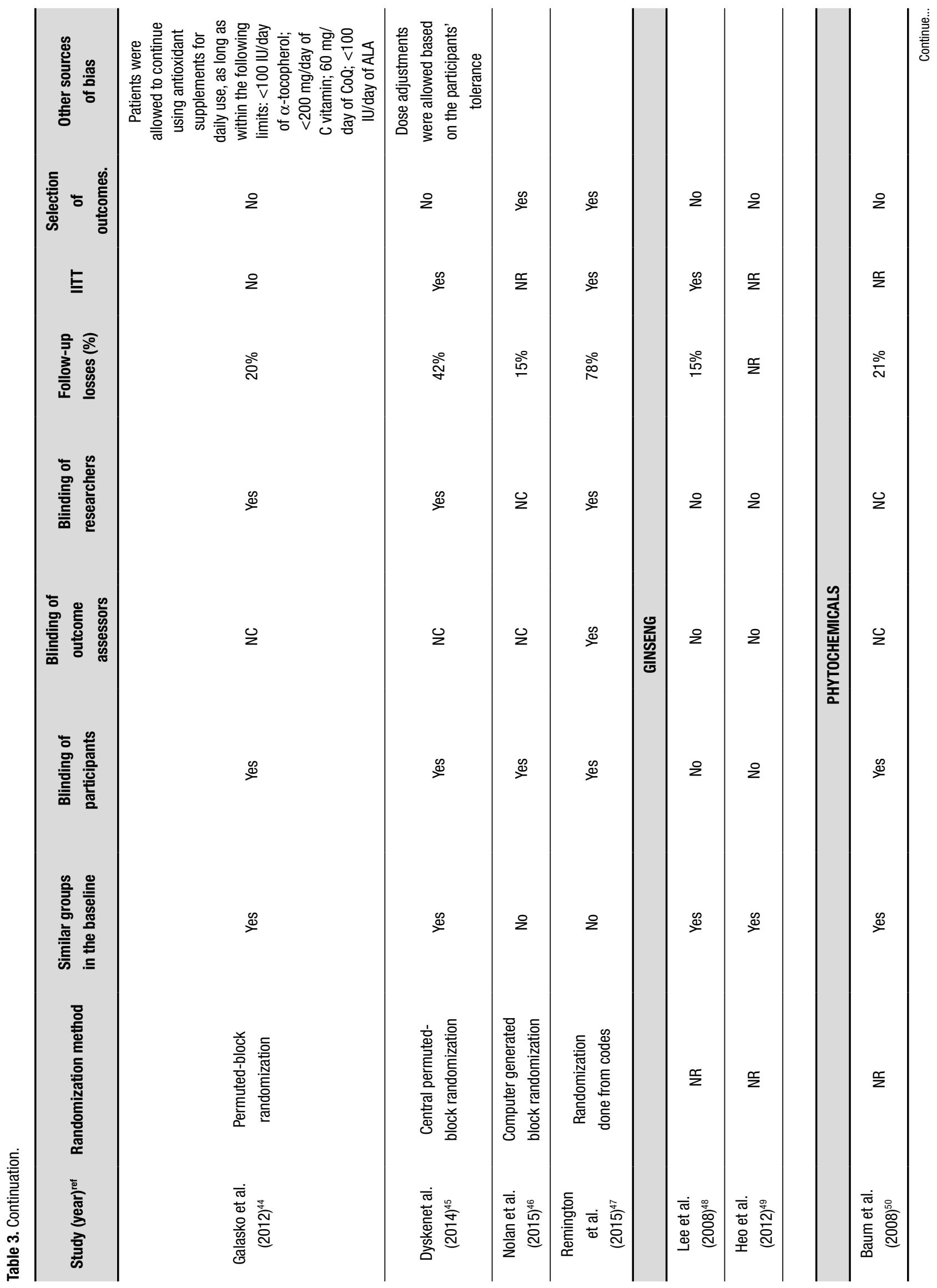




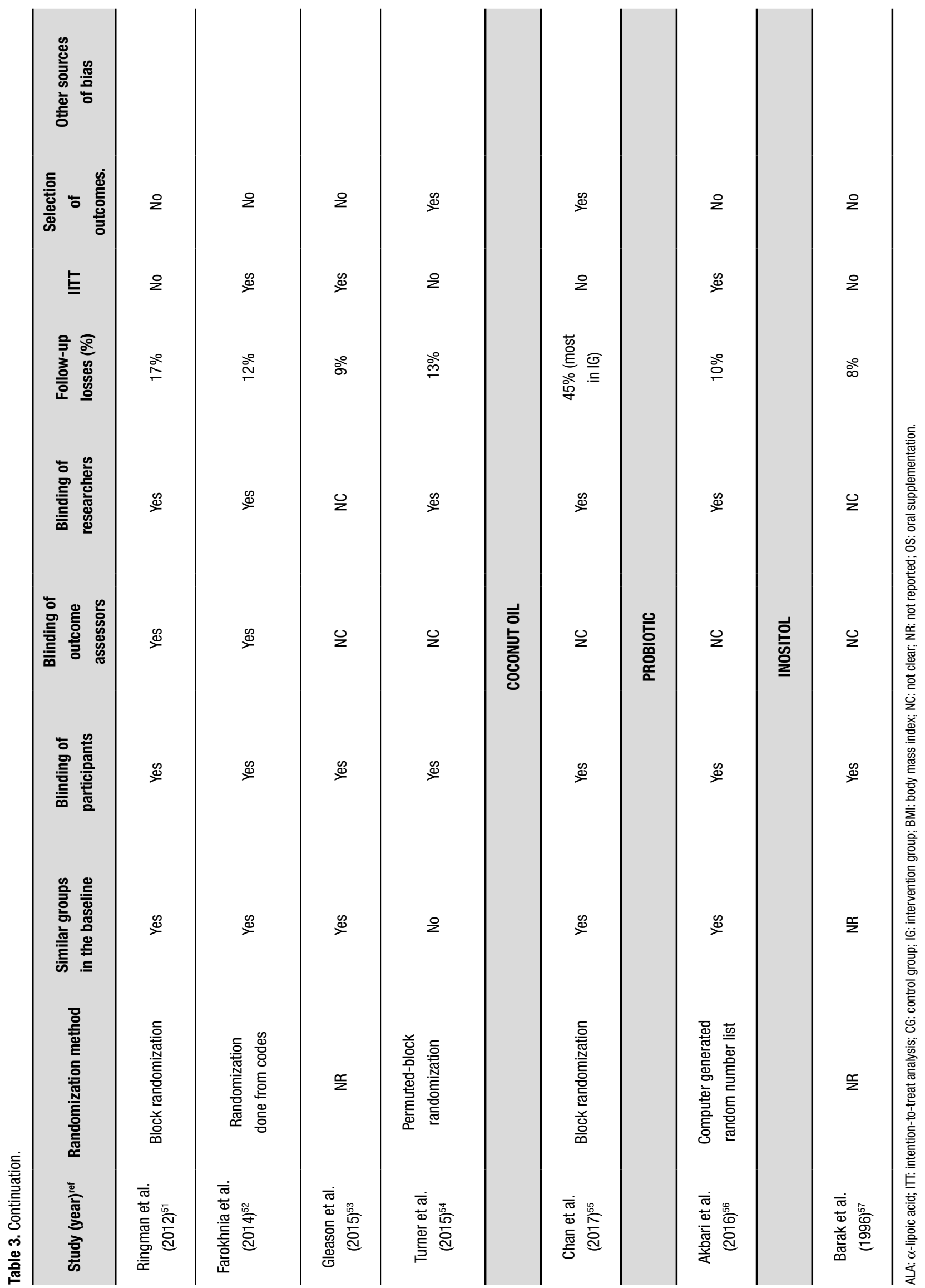


In patients with mild to severe $\mathrm{AD}$, supplementation with vitamin $\mathrm{E}$ alone (800 IU/day) proved to be ineffective and, for some participants, harmful. Comparing intervention and control groups, supplement use did not alter cognitive performance in the MMSE, CLOX-1, and Blessed Dementia Scale. However, patients that at the end of the intervention did not obtain a reduction on serum oxidized glutathione levels, considered "unresponsive" to treatment with vitamin E, had a significant decline in MMSE when compared to "responsive" ones. ${ }^{42}$

Similar results in MMSE performance were also found with vitamin E supplementation (800 IU/day) associated with vitamin C (500 mg/day) and ALA (900 $\mathrm{mg} /$ day).$^{44}$ Compared to the control, the supplemented group showed a significant reduction in MMSE performance. Paradoxically, in the same group, there was a decline in levels of F2-isoprostane relative to baseline, a biomarker of oxidative damage.

Of the five other studies, two compared $\alpha$-tocopherol supplementation with pharmacological treatment $\left(\right.$ Selegiline ${ }^{38}$ and Memantine ${ }^{45}$ ), one analyzed the effect of methylcobalamin supplementation in combination with multivitamin, ${ }^{39}$ one used a combination of folic acid, vitamin B12 and pyridoxine ${ }^{41}$ and one a carotenoid supplement containing mezo-zeaxanthin, lutein, and zeaxanthin. ${ }^{46}$ In none of these trials, however, the results found were significant for the cognitive parameters evaluated.

The randomization method used to allocate participants was described in eight of the ten studies. Of these, five $\mathrm{e}^{16,38,41,44}$ used permuted block randomization, two ${ }^{39,42}$ were randomized using a list of random numbers, and one ${ }^{47}$ used code randomization.

The studied groups were comparable at baseline in seven ${ }^{38-42,44,45} \mathrm{RCT}$, and in $\mathrm{two}^{43,37}$ of the remainder these data were not reported. All trials showed follow-up losses greater than $10 \%$ for the most part of the studies. ${ }^{39-47}$ Five studies ${ }^{38,41,43,45,47}$ performed the ITT and two did not report the type of analysis performed. ${ }^{58,46}$ Regarding the evaluated outcomes, two studies ${ }^{46,47}$ did not present the results of all pre-established outcomes.

\section{Ginseng}

Two open parallel trials evaluated ginseng supplementation in individuals with $\mathrm{AD} .{ }^{48,49}$ The duration of interventions varied between 12 and 24 weeks and the studies were heterogeneous in terms of sample size (58-97 subjects), doses, and types of ginseng used.

In both trials, ginseng supplementation resulted in significant improvement in the cognitive outcomes evaluated. Patients with moderate to severe $\mathrm{AD}$ (MMSE<20 and CDR score $>1$ ) treated with $4.5 \mathrm{~g} / \mathrm{d}$ of Sun Ginseng
(SG-135) showed significant improvement in the ADAScog and MMSE after 12 and 24 weeks of supplementation. ${ }^{49}$ Similar results were found with the use of 4.5 and $9.0 \mathrm{~g} / \mathrm{d}$ of Korean white ginseng in a sample of patients with mild to moderate AD. Compared to control, both doses resulted in improvement in the MMSE and ADAScog scores after 12 weeks of supplementation and such effect was eliminated 12 weeks after discontinuation of treatment. ${ }^{49}$

The groups studied were comparable at baseline in both RCT. A follow-up loss of $15 \%$ was reported by one of the trials, which performed an ITT analysis. ${ }^{48}$ In the other trial, information about follow-up losses and data analysis method were not reported. ${ }^{49}$ In both trials, the results of all predetermined outcomes were presented.

\section{Phytochemicals}

Five parallel double-blind $\mathrm{RCT}^{50-54}$ evaluated the effect of supplementation of different phytochemicals extracted from foods and condiments compared with placebo $^{50,51,53,54}$ or pharmacological treatment. ${ }^{52}$ Of the five trials, two evaluated the effect of turmeric at different doses and concentrations of curcuminoids, ${ }^{50,51}$ one used dried turmeric extract, ${ }^{52}$ one purified soy isoflavone, ${ }^{53}$ and another, steady doses of Resveratrol..$^{54}$ In none of the trials, however, the results found were significant for the cognitive parameters evaluated.

Heterogeneity among studies was observed in relation to sample size (34-119 subjects per trial), degree of cognitive decline (mild to severe), duration of the intervention (6 to 13 months), and cognitive outcomes (ADAS-cog, CDR-SOB, MMSE, and Severe Cognitive Impairment Rating Scale — SCIRS).

The randomization method used to allocate participants was described in three of the five studies. Of these, two ${ }^{51,54}$ used block randomization and one $\mathrm{e}^{52}$ had randomization carried out from codes that were kept in opaque, sealed, and sequentially numbered envelopes.

The groups studied were comparable at baseline in four RCT. ${ }^{50-53}$ All trials had follow-up losses greater than $10 \%$ in most studies. ${ }^{50-52,54}$ Of the five trials, two $^{52,53}$ performed ITT and one did not report the type of analysis performed. ${ }^{50}$ As for the outcomes evaluated, four of the five studies ${ }^{50-53}$ presented the results of all pre-established outcomes.

\section{Coconut oil}

A parallel, double-blind, placebo-controlled $\mathrm{RCT}^{55}$ evaluated the effect of coconut oil on the cognitive performance of subjects with mild to moderate AD. Using the 
block randomization method, 58 subjects were randomized to receive coconut oil or placebo. The characteristics of the groups were similar at baseline. After 6 months of intervention, no change was observed in the cognitive performance assessed by MMSE and CLOX-1.

Regarding the methodological quality, the study showed a $45 \%$ loss of follow-up, which was higher in the intervention group due to side effects such as diarrhea and abdominal discomfort. Data analysis was performed per protocol and the results of all pre-established outcomes were not presented.

\section{Probiotics}

A parallel, double-blind, placebo-controlled $\mathrm{RCT}^{56}$ assessed the effect of probiotic supplementation onIN 60 patients with advanced AD. Using a computer program to generate a random list, participants were randomly allocated to receive milk with probiotics (L. Acidophilus, L. Casei. B. Bifidum, and L. Fermentum) or placebo. After 12 weeks of intervention, the probiotic supplemented group had a significant improvement in MMSE performance.

Regarding methodological quality, the groups were different at baseline in relation to some metabolic parameters (triglyceride levels, high density lipoprotein - HDL, and very low density lipoprotein - VLDL), but had similar cognitive characteristics. The follow-up loss was $10 \%$ and data were analyzed by ITT. The blinding of participants and researchers was maintained until the analysis conclusion and all the pre-established outcomes were reported.

\section{$\underline{\text { Inositol }}$}

The effect of inositol supplementation was evaluated on a double-blind, placebo-controlled crossover RCT. ${ }^{57}$ Twelve women with mild to severe $\mathrm{AD}$ were randomly allocated to receive inositol or dextrose (placebo). After 4 weeks of treatment, supplementation resulted in a significant improvement in the orientation and language domains assessed by the Cognitive Subscale of Cambridge Mental Disorder of the Elderly Examination (CAMCOG).

Regarding the methodological quality, the randomization method used was not reported in the study, there was a loss of $8 \%$ follow-up and data analysis was performed per protocol.

\section{DISCUSSION}

This systematic review aimed to evaluate the effect of different dietary interventions on the management of cognitive decline in $\mathrm{AD}$ patients.
Our study indicates the effects of improving or delaying cognitive decline with the use of specialized nutritional formulas, fatty acid supplements, ginseng, inositol probiotics. However, it is noteworthy that such results were mostly obtained in patients with mild $A D$, limited to only one part of the cognitive outcomes evaluated and resulted from the use of associated and not isolated nutrients in most trials, which suggests that the observed effects may (or may not) be due to the association of rather than a single target nutrient.

Regarding specialized oral nutritional formulations, in the prodromal phase and in the early stages of the disease, Fortasyn Connect $\left(\right.$ Souvenaid $^{\circledR}$ ), an oral supplement that includes a combination of EPA, DHA, phospholipids, uridine monophosphate, choline, selenium, and vitamins B6, B12, B9, C, and E, showed good results in the patients' cognitive performance.

Suggested mechanisms for the effects of Fortasyn Connect include increased bioavailability of precursors and co-factors required for neuronal formation, maintenance and function, increased acetylcholine levels and cholinergic receptors with consequent stimulation of synaptogenesis and reduction of $A \beta$ production and neurotoxicity ${ }^{58}$ However, despite the promising therapeutic effect of prodromal AD, the effects of supplementation with Fortsasyn Connect are still divergent in patients with mild to moderate disease, and further studies are needed to elucidate differences in the outcomes and to confirm the existence of therapeutic benefits on cognition.

The neuroprotective action of omega-3 fatty acids, especially DHA, has been demonstrated in several in vitro experiments and in animal models of $\mathrm{AD}$, reinforcing the idea that supplementation of these nutrients could help reduce neuroinflammation and cognitive decline. ${ }^{59}$ In mouse models of $\mathrm{AD}$, DHA treatment resulted in reduced brain levels of $A \beta$, particularly $\beta$-Amyloid 42 $(\mathrm{A} \beta-42)$, the main component of amyloid plaques that contributes to irreversible neuronal death and rapid disease progression. Other mechanisms involved in the action of DHA include anti-inflammatory, antioxidant, and anti-apoptotic effects. ${ }^{59}$

Neuroinflammation, chronic activation of glial cells and increased production of reactive oxygen species are involved in the pathogenesis and progression of $\mathrm{AD}$. In in vitro studies and in patients with $\mathrm{AD}, \mathrm{DHA}$ administration was able to induce microglial phagocytosis of $A \beta-42$, decrease IL-1beta, IL- 6 production and the activation of proinflammatory transcription of the nuclear factor Kappa B (NFKB). ${ }^{59}$ In animal models of AD, treatment with DHA has also been shown to increase levels of antioxidant enzymes catalase and glutathione 
peroxidase, as well as to reduce oxidative damage to the cerebral cortex and hippocampal cells. ${ }^{59}$

Oxidative stress-induced by $\mathrm{A} \beta$ deposition is primarily responsible for TP hyperphosphorylation, which is associated with neuronal damage and induction of an apoptotic cascade. ${ }^{59}$ In addition to the antioxidant effects already mentioned, DHA performance includes the regulation of the apoptotic cascade induced by $A \beta$ at the level of lipid peroxides, conferring neuroprotection to neuronal cells. However, the effects of DHA on cognitive function and $\mathrm{AD}$ progression are absent in individuals who possess the APOE $\varepsilon 4$ allele, which is associated with lower DHA uptake in the brain. ${ }^{59}$

In the three studies that evaluated the use of omega-3 in $\mathrm{AD},{ }^{35-37}$ supplementation was effective in delaying cognitive decline in individuals with $\mathrm{AD}$, but there was a significant variation between studies in relation to the doses, proportion of EPA and DHA and association of antioxidants (only one study used DHA alone). Adverse effects were also reported in the studies, including changes in the International Normalized Ratio (INR) in subjects taking warfarin ${ }^{36}$ and with diarrhea. ${ }^{35,37}$

Improvement in several cognitive domains was also observed in a study of patients with advanced stages of the disease who were supplemented with a mixture of $\alpha$-Linolenic fatty acids and Linoleic acid. ${ }^{34}$ However, some methodological flaws of the study should be considered, including the use of an invalidated instrument for cognitive assessment and the absence of statistical treatment adjusting for confounding factors. Thus, other studies with greater methodological rigor are necessary to confirm the efficacy in the cognitive improvement of patients with AD.

Among micronutrient supplements, only supplementation with formula containing folic acid, vitamin B12, $\alpha$-tocopherol, S-adenosyl methionine, N-acetyl cysteine, and acetyl-L-carnitine showed positive results in the cognitive performance of $\mathrm{AD}$ patients. ${ }^{47} \mathrm{In}$ in vitro experiments and in animal models of $A D$, the administration of such components has been associated with reduced oxidative stress and decreased $A \beta$ production and TP phosphorylation. ${ }^{43}$ However, such results should be interpreted with caution due to limitations and methodological flaws of the study.

Ginsenoside administration in AD animal models has been shown to be associated with a neuroprotective effect and better memory performance..$^{60}$ In the two studies in this review that evaluated Ginseng supplementation, ${ }^{48,49}$ the treated groups demonstrated better cognitive performance in ADAS-cog and MMSE. However, limitations in the methodological quality of the trials do not allow us to draw a conclusion about the benefits found. Therefore, further studies with better methodological quality are necessary to evaluate the use of Ginseng supplementation in individuals with $A D$.

In individuals with advanced $\mathrm{AD}$, supplementation for three months of a probiotic milk containing Lactobacillus acidophilus, Lactobacillus casei, Bifidobacteriumbifidum, and Lactobacillus fermentum resulted in improved performance in MMSE, but the mechanisms for this finding still need clarification. ${ }^{56}$ Thus, further studies are needed to confirm this therapeutic potential and to elucidate the mechanism by which probiotics interfere with the neurodegenerative process of $\mathrm{AD}$.

The use of inositol resulted in improved performance of $\mathrm{AD}$ patients in orientation and language cognitive domains ${ }^{57}$ However, this effect should be interpreted with caution once it was only a small trial and the sample was heterogeneous in relation to educational level, time of diagnosis and phase of dementia, factors that are known to influence cognitive performance. Therefore, further studies are needed to confirm a possible benefit with inositol supplementation.

Other interventions included the use of B-complex vitamins, Copper Orate, $\alpha$-tocopherol, carotenoids, turmeric, soy isoflavones, resveratrol, and coconut oil, but there was no evidence of benefit in cognition in the studies.

The limitations of this review should be considered and include the limitation of articles in English and the impossibility of performing a meta-analysis due to methodological differences and the limited extent of available literature.

The strengths of this paper should also be highlighted and include the search in three databases, reading of titles and abstracts by two researchers and unlimited search for the date of publication of the articles.

The present systematic review points out that the effect of most dietary interventions on cognition in $\mathrm{AD}$ patients is inconclusive due to limited scientific evidence due to the poor methodological quality of the primary studies and the reduced number of studies. However, several nutrients associated and isolated DHA derived from algae show potential to improve cognitive function in $\mathrm{AD}$, especially in its early stages. Thus, in a challenging scenario with a significant increase in the number of diagnoses of $\mathrm{AD}$, better quality studies are urgently needed to confirm the therapeutic potential of the diet so that a dietary recommendation in $\mathrm{AD}$ that contributes to the quality of life of patients and relatives can be established.

Authors' contributions. SCM, AKJ and FMS: methodology, supervision, writing - review \& editing. 


\section{REFERENCES}

1. Petterson C. World Alzheimer Report 2018. The state of the art of dementia research: New frontiers. London: Alzheimer's Disease International; 2018

2. Cohen RM. Epidemiology and clinical diagnosis; Alzheimer disease. PET Clin. 2013;8(4):391-405. https://doi.org/10.1016/j.cpet.2013.08.001

3. Reitz C, Mayeux R. Alzheimer disease: epidemiology, diagnostic criteria risk factors andbiomarkers. Biochem Pharmacol. 2014;88(4):640-51. https://doi.org/10.1016/j.bcp.2013.12.024

4. Herrera Jr E, Caramelli P, Silveira AS, Nitrini R. Epidemiologic survey of dementia in a community-dwelling Brazilian population. Alzheimer Dis Assoc Disord. 2002;16(2):103-8. https://doi.org/10.1097/00002093200204000-00007

5. Bottino CM, Azevedo DJ, Tatsch M, Hototian SR, Moscoso MA, Folquitto $A Z$, et al. Estimate of dementia prevalence in a community sample from São Paulo, Brazil. Dement Geriatr Cogn Disord. 2008;26(4):291-9. https:// doi.org/10.1159/000161053

6. Scheltens P, Blennow K, Breteler MM, de Strooper B, Frisoni GB, Salloway S, et al. Alzheimer's disease. Lancet. 2016;388(10043):505-17. https:// doi.org/10.1016/S0140-6736(15)01124-1

7. Cavalcanti JLS, Engelhardt E. Aspectos da fisiopatologia da doença de Alzheimer esporádica. Rev Bras Neurol. 2012;48(4):21-9.

8. Kumar A, Singh A, Ekavali. A review on Alzheimer's disease pathophysiology and its management: an update. Pharmacol Rep. 2015;67(2):195-203. https://doi.org/10.1016/j.pharep.2014.09.004

9. Dubois B, Hampel H, Feldman HH, Sheltens P, Aisen P, et al. Preclinical Alzheimer's disease: definition, natural history, and diagnostic criteria. Alzheimers Dement. 2016;12(3):292-323. https://doi.org/10.1016/j. jalz.2016.02.002

10. Huang $Y$, Mucke L. Alzheimer mechanisms and therapeutic strategies. Cell. 2012;148(6):1204-22. https://doi.org/10.1016/j.cell.2012.02.040

11. Honig LS, Boyd CD. Treatment of Alzheimer's disease: current management and experimental therapeutics. Curr Transl Geriatr Exp Gerontol Rep. 2013;2(3):174-81. https://doi.org/10.1007/s13670-013-0056-3

12. Zhou X, Li Y, Shi X, Ma C. An overview on therapeutics attenuating amyloid $\beta$ level in Alzheimer's disease: targeting neurotransmission, inflammation, oxidative stress and enhanced cholesterol levels. Am J Transl Res. 2016;8(2): 246-69.

13. Morris MC, Tangney CC, Wang Y, Sacks FM, Bennett DA, Aggarwal NT. MIND diet associated with reduced incidence of Alzheimer's disease. Alzheimers Dement. 2015;11(9):1007-14. https://doi.org/10.1016/j. jalz.2014.11.009

14. Galbete C, Toledo E, Toledo JB, Bes-Rastrollo M, Buil-Cosiales P, Marti A, Guillén-Grima F, Martínez-González MA. Mediterranean diet and cognitive function: The SUN project. J Nutr Health Aging. 2015;19(3):305-12. https://doi.org/10.1007/s12603-015-0441-z

15. Trichopoulou A, Kyrozis A, Rossi M, Katsoulis M, Trichopoulos D, La Vecchia $\mathrm{C}$, et al. Mediterranean diet and cognitive decline over time in an elderly Mediterranean population. Eur J Nutr. 2015;54(8):1311-21. https:// doi.org/10.1007/s00394-014-0811-z

16. Tangney CC, Li H, Wang Y, Barnes L, Schneider JA, Bennett DA, et al. Relation of DASH- and Mediterranean-like dietary patterns to cognitive decline in older persons. Neurol. 2014;83(16):1410-6. https://doi. org/10.1212/WNL.0000000000000884

17. Morris MC, Tangney CC, Wang Y, Sacks FM, Barnes LL, Bennett DA, et al. MIND diets lows cognitive decline with aging. Alzheimers Dement. 2015;11(9):1015-22. https://doi.org/10.1016/j.jalz.2015.04.011

18. Pelletier A, Barul C, Féart C, Helmer C, Bernard C, Periot O, et al. Mediterranean diet and preserved brain structural connectivity in older subjects. Alzheimers Dement. 2015;11(9):1023-31. https://doi.org/10.1016/j. jalz.2015.06.1888

19. Berti V, Walters M, Sterling J, Quinn CG, Logue M, Andrews R, et al. Mediterranean diet and 3-year Alzheimer brain biomarker changes in middle-aged adults. Neurology. 2018;90(20):e1789-e1798. https://doi. org/10.1212/WNL.0000000000005527

20. Yusufov M, Weyandt LL, Piryatinsky I. Alzheimer's disease and diet: a systematic review. Int J Neurosci. 2017;127(2):161-75. https://doi.org/1 0.3109/00207454.2016.1155572

21. Dangour AD, Whitehouse PJ, Rafferty K, Mitchell SA, Smith L, Hawkesworth S, et al. B-vitamins and fatty acids in the prevention and treatment of Alzheimer's disease and dementia: a systematic review. J Alzheimers Dis. 2010;22(1):205-24. https://doi.org/10.3233/jad-2010-090940

22. Ramesh BN, Sathyanarayana Rao TS, Prakasam A, Sambamurti K, Jagannatha Rao KS. Neuronutrition and Alzheimer's disease. J Alzheimers Dis. 2010;19(4):1123-39. https://doi.org/10.3233/jad-2010-1312

23. Essa MM, Vijayan RK, Castellano-Gonzales G, Memon MA, Braidy N, Guillemin GJ. Neuroprotective effect of natural products against Alzheimer's disease. Neurochem Res. 2012;37(9):1829-42. https://doi.org/10.1007/ s11064-012-0799-9

24. Higgnis JPT, Green S, editors. Cochrane Handbook for Systematic Reviews of Interventions Version 5.0.1 [updates September 2008]. The Cochrane Collaboration; 2008 [accessed on Jan 10, 2017]. Available at: www.cochrane-handbook.org.

25. Moher D, Liberati A, Tetzlaff J, Altman DG, PRISMA Group. Preferred reporting items for systematic reviews and meta-analyses: the PRISMA statement. J Clin Epidemiol. 2009;62(10):1006-12. https://doi.org/10.1016/j. jclinepi.2009.06.005

26. Lauque S, Arnaud-Battandier F, Gillette S, Plaze JM, Andrieu S, Cantet $\mathrm{C}$, et al. Improvement of weight and fat-free mass with oral nutritional supplementation in patients with Alzheimer's disease at risk of malnutrition: A prospective randomized study. J Am Geriatr Soc. 2004;52(10):1702-7. https://doi.org/10.1111/j.1532-5415.2004.52464.x

27. Planas M, Conde M, Audivert S, Pérez-Portabella C, Burgos R, Chacón P, et al. Micronutrient supplementation in mild Alzheimer disease patients. Clin Nutr. 2004;23(2):265-72. https://doi.org/10.1016/s02615614(03)00106-7

28. Salas-Salvadó J, Torres M, Planas M, Altimir S, Pagan C, Gonzalez ME, et al. Effect of oral administration of a whole formula diet on nutritional and cognitive status in patients with Alzheimer's disease. Clin Nutr. 2005;24(3):390-7. https://doi.org/10.1016/j.clnu.2004.12.006

29. Scheltens P, Kamphuis PJ, Verhey FR, Olde Rikkert MG, Wurtman RJ, Wilkinson D, et al. Efficacy of a medical food in mild Alzheimer's disease: A randomized controlled trial. Alzheimers Dement. 2010;6(1):1-10.e1. https://doi.org/10.1016/j.jalz.2009.10.003

30. De Sousa OL, Amaral TF. Three-week nutritional supplementation effect on long-term nutritional status of patients with mild Alzheimer disease. Alzheimer Dis Assoc Disord. 2012;26(2):119-23. https://doi.org/10.1097/ wad.0b013e31822c5bb3

31. Scheltens P, Twisk JWR, Blesa R, Scarpini E, Von Arnim CAF, Bongers A, et al. Efficacy of souvenaid in mild Alzheimer's disease: Results from a randomized, controlled trial. J Alzheimers Dis. 2012;31(1):225-36. https:// doi.org/10.3233/jad-2012-121189

32. Shah RC, Kamphuis PJ, Leurgans S, Swinkels SH, Sadowsky CH, Bongers A. The S-Connect study: results from a randomized, controlled trial of souvenaid in mild-to-moderate Alzheimer's disease. Alzheimers Res Ther. 2013;5(6):59. https://doi.org/10.1186/alzrt224

33. Soininen $\mathrm{H}$, Solomon A, Visser PJ, Hendrix SB, Blennow $\mathrm{K}$, Kivipelto $M$, et al. 24-month intervention with a specific multinutrient in people with prodromal Alzheimer's disease (LipiDiDiet): a randomised, double-blind, controlled trial. Lancet Neurol. 2017;16(12):965-75. https://doi. org/10.1016/S1474-4422(17)30332-0

34. Yehuda S, Rabinovtz S, Carasso RL, Mostofsky DI. Essential fatty acids preparation (SR-3) improves Alzheimer's patients quality of life. Intern J Neurosci. 1996;87(3-4):141-9. https://doi.org/10.3109/00207459609070833

35. Freund-Levi Y, Eriksdotter-Jönhagen M, Cederholm T, Basun H, Faxén-Irving $\mathrm{G}$, Garlind $\mathrm{A}$, et al. Omega-3 fatty acid treatment in 174 patients with mild to moderate Alzheimer disease: OmegAD study: a randomized double-blind trial. Arch Neurol. 2006;63(10):1402-8. https://doi.org/10.1001/ archneur.63.10.1402

36. Quinn JF, Raman R, Thomas RG, Yurko-Mauro K, Nelson EB, van Dyck $\mathrm{C}$, et al. Docosahexaenoic acid supplementation and cognitive decline in Alzheimer disease: a randomized trial. JAMA. 2010;304(17):1903-11. https://doi.org/10.1001/jama.2010.1510

37. Shinto L, Quinn J, Montine T, Dodge HH, Woodward W, Baldauf-Wagner $S$, et al. A randomized placebo-controlled pilot trial of omega-3 fatty acids and alpha lipoic acid in Alzheimer's disease. J Alzheimers Dis. 2014;38(1):111-20. https://doi.org/10.3233/JAD-130722

38. Sano M, Ernesto C, Thomas RG, Klauber MR, Shafer K, Grundman M, et al. A controlled trial of selegiline, alpha-tocopherol, or both as treatment for Alzheimer's disease. N Engl J Med. 1997;336(17):1216-22. https:// doi.org/10.1056/nejm199704243361704

39. Sun Y, Lu CJ, Chien KL, Chen ST, Che RC. Efficacy of multivitamin supplementation containing vitamins B6 and B12 and folic acid as adjunctive treatment with cholinesterase inhibitor in Alzheimer's disease: a 26-week, randomized, double-blind, placebo-controlled study in Taiwanese patients. Clin Ther. 2007;29(10):2204-14. https://doi.org/10.1016/j. clinthera.2007.10.012

40. Kessler H, Bayer TA, Bach D, Schneider-Axmann T, Supprian T, Herrmann $W$, et al. Intake of copper has no effect on cognition in patients with mild Alzheimer's disease: a pilot phase 2 clinical trial. J Neural Transm (Vienna). 2008;115(8):1181-7. https://doi.org/10.1007/s00702-008-0080-1 
41. Aisen PS, Schneider LS, Sano M, Diaz-Arrastia R, van Dyck $\mathrm{CH}$, Weiner $\mathrm{MF}$, et al. High-dose B vitamin supplementation and cognitive decline in Alzheimer disease: a randomized controlled trial. JAMA. 2008;300(15):177483. https://doi.org/10.1001/jama.300.15.1774

42. Lloret A, Badía M, Mora NJ, Pallardó FV, Alonso M, Viña J. Vitamin E paradox in Alzheimer's disease: it does not prevent loss of cognition and may even be detrimental. J Alzheimers Dis. 2009;17(1):143-9. https://doi. org/10.3233/jad-2009-1033

43. Remington R, Chan A, Paskavitz J, Shea TB. Efficacy of a vitamin/ nutriceutical formulation for moderate-stage to later-stage Alzheimer's disease: a placebo-controlled pilot study. Am J Alzheimers Dis Other Demen. 2009:24(1):27-33. https://doi.org/10.1177/1533317508325094

44. Galasko DR, Peskind E, Clark CM, Quinn JF, Ringman JM, Jicha GA, et al. Antioxidants for Alzheimer disease: a randomized clinical trial with cerebrospinal fluid biomarker measures. Arch Neurol. 2012;69(7):836-41. https://doi.org/10.1001/archneurol.2012.85

45. Dysken MW, Sano M, Asthana S, Vertrees JE, Pallaki M, Llorente M, et al. Effect of vitamin $E$ and memantine on functional decline in Alzheimer disease: the TEAM-AD VA cooperative randomized trial. JAMA. 2014:311(1):33-44. 10.1001/jama.2013.282834

46. Nolan JM, Loskutova E, Howard A, Mulcahy R, Moran R, Stack J, et al. The impact of supplemental macular carotenoids in Alzheimer's disease: a randomized clinical trial. J Alzheimers Dis. 2015;44(4):1157-69. https:// doi.org/10.3233/jad-142265

47. Remington R, Bechtelb C, Larsenc D, Samard A, Doshanjhf L, Fishman P, et al. A phase ii randomized clinical trial of a nutritional formulation for cognition and mood in Alzheimer's disease. J Alzheimers Dis. 2015;45(2):395405. https://doi.org/10.3233/jad-142499

48. Lee ST, Chu K, Sim JY, Heo JH, Kim M. Panax ginseng enhances cognitive performance in Alzheimer disease. Alzheimer Dis Assoc Disord. 2008:22(3):222-6. https://doi.org/10.1097/WAD.0b013e31816c92e6

49. Heo JH, Lee ST, Chu K, Oh MJ, Park HJ, Shim JY, et al. Heat-processed ginseng enhances the cognitive function in patients with moderately severe Alzheimer's disease. Nutr Neurosci. 2012;15(6):278-82. https://doi.org/1 0.1179/1476830512y.0000000027

50. Baum L, Lam CW, Cheung SK, Kwok T, Lui V, Tsoh J, et al. Six-month randomized, placebo-controlled, double-blind, pilot clinical trial of curcumin in patients with Alzheimer disease. J Clin Psychopharmacol. 2008;28(1):110-3. https://doi.org/10.1097/jcp.0b013e318160862c

51. Ringman JM, Frautschy SA, Teng E, Begum AN, Bardens J, Beigi M, et al. Oral curcumin for Alzheimer's disease: tolerability and efficacy in a 24-week randomized, double blind, placebo-controlled study. Alzheimers Res Ther. 2012;4(5):43. https://doi.org/10.1186/alzrt146

52. Farokhnia M, Shafiee Sabet M, Iranpour N, Gougol A, Yekehtaz H, Alimardani R, et al. Comparing the efficacy and safety of Crocus sativus L. with memantine in patients with moderate to severe Alzheimer's disease: A double-blind randomized clinical trial. Hum Psychopharmacol. 2014;29(4):351-9. https://doi.org/10.1002/hup.2412

53. Gleason CE, Fischer BL, Dowling NM, Setchell KD, Atwood CS, Carlsson $\mathrm{CM}$, et al. Cognitive effects of soy isoflavones in patients with Alzheimer's disease. J Alzheimers Dis. 2015;47(4):1009-19. https://doi.org/10.3233/ jad-142958

54. Turner RS, Thomas RG, Craft S, van Dyck CH, Mintzer J, Reynolds BA, et al. A randomized, double-blind, placebo-controlled trial of resveratrol for Alzheimer disease. Neurology. 2015;85(16):1383-91. https://doi. org/10.1212/WNL.0000000000002035

55. Chan SC, Esther GE, Yip HL, Sugathan S, Chin PS. Effect of cold pressed coconut oil on cognition and behavior among patients with Alzheimer's disease - A pilot intervention study. Natl J Physio Pharm Pharmacol. 2017;7(12):1432-5. https://doi.org/10.5455/ njppp.2017.0829311082017

56. Akbari E, Asemi Z, Kakhaki RD, Bahmani F, Kouchaki E, Tamtaji OR, et al. Effect of probiotic supplementation on cognitive function and metabolic status in Alzheimer's disease: a randomized, double-blind and controlled trial. Front Aging Neurosci. 2016;10(8):256. https://doi.org/10.3389/ fnagi.2016.00256

57. Barak Y, Levine J, Glasman A, Elizur A, Belmaker RH. Inositol treatment of alzheimer's disease. a double blind, cross-over placebo controlled trial. Prog Neuropsychopharmacol Biol Psychiatr. 1996;20(4):729-35. https:// doi.org/10.1016/0278-5846(96)00043-7

58. van Wijk N, Broersen LM, de Wilde MC, Hageman RJ, Groenendijk M, Sijben JW, et al. Targeting synaptic dysfunction in Alzheimer's disease by administering a specific nutrient combination. J Alzheimers Dis. 2014;38(3):459-79. https://doi.org/10.3233/jad-130998

59. Belkouch $M$, Hachem M, Elgot A, Van AL, Picq M, Guichardant M, et al. The pleiotropic effects of omega-3 docosahexaenoic acid on the hallmarks of Alzheimer's disease. J Nutr Biochem. 2016;38:1-11. https:// doi.org/10.1016/j.jnutbio.2016.03.002

60. Sheng C, Peng W, Xia ZA, Wang Y, Chen Z, Su N, et al. The impact of ginsenosides on cognitive deficits in experimental animal studies of Alzheimer's disease: a systematic review. BMC Complement Altern Med. 2015;15:1-15. https://doi.org/10.1186/s12906-015-0894-y 